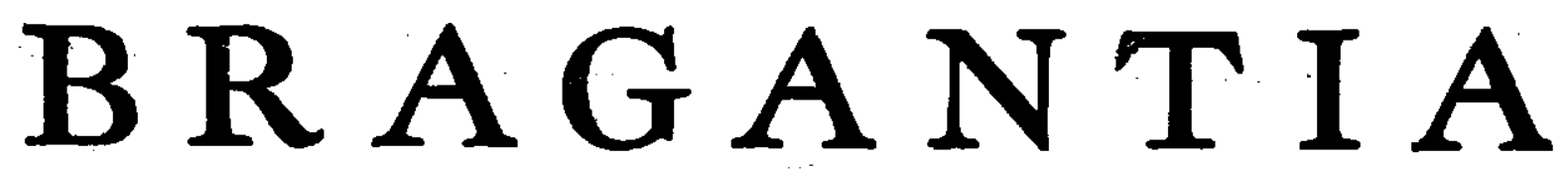

Boletim Técnico do Instituto Agronômico do Estado de São Paulo

Vol. I Campinas, Agosto-Setembro de 1941 N. os $_{\text {8-9 }}$

\title{
EXPERIÊNCIAS DE CAVALOS PARA CITRUS I
}

\section{Sílvio Moreira}

\section{A) - CONSIDERAÇÕES GERAIS}

O problema de cavalos para citrus no Estado de São Paulo não se apresenta, como acontece em muitas outras regiões citrícolas do globo $(4,8,9,14,15,17,20)$, com grandes e prementes dificuldades. Isto se deve principalmente à feliz circunstância de que a laranja azeda (C. aurantium L.) encontra em nosso meio condições muito favoraveis ao seu desenvolvimento. Cavalo universalmente reconhecido como portador de ótimas caraterísticas em relação à resistência a certas moléstias graves (5), possue tambem a laranja azeda boa afinidade para com a maior parte das variedades cítricas cultivadas comercialmente entre nós. Em relação às qualidades conferidas às frutas das variedades nela enxertadas, coloca-se ainda, a laranja azeda, entre os cavalos mais apreciados (8).

Ao se iniciar a grande expansão das plantações cítricas no Estado, lá pelo ano de 1928, muito se discutiu, entre técnicos e citricultores, sobre qual a espécie e variedade mais indicada para servir de base aos nossos novos laranjais (1). Em que pese a teimosia de alguns citricultores partidários da laranja caipira ( $C$. sinensis Osbeck) ou da lima da Pérsia (C. aurantifolia Swingle), dominou literalmente a ala que, baseando-se na valiosa experiência de outros povos, propugnava pela adoção do cavalo de laranja azeda.

Entretanto, considerando-se que quase toda a área do Estado de São Paulo goza de clima favoravel à cultura cítrica, e que, dentro dessa vasta superfície, existem 22 tipos principais de solo (21), não é de se esperar que a laranja azeda ou qualquer outra variedade-cavalo se adapte otimamente em todo o Estado. 
Por outro lado, deve-se esperar comportamento diferente de uma dada variedade-cavalo para com as diversas variedades-enxerto cultivadas comercialmente entre nós.

Em vista das considerações acima, procurando estabelecer experimentalmente a situação real do problema dos porta-enxertos para nossas principais variedades comerciais, iniciamos em 1933, na Estação Experimental de Limeira, os trabalhos preliminares para a instalação dos ensaios que são objeto desta série de publicações (26).

plano dessas experiências comporta observações sobre:

a) Desenvolvimento das plantas;

b) Produção (frutos) qualitativa e quantitativa ;

c) Suscetibilidade a moléstias e pragas ;

d) Interação entre cavalos e enxertos;

e) Longevidade das plantas.

Outra experiência sobre cavalos para citrus foi iniciada, tambem em 1933, pelo agrônomo J. A. Santos Neto, atual Chefe da Estação Experimental de Ribeirão-Preto, onde se instalou o ensaio em plantação definitiva (pomar). Até o presente momento nenhum resultado foi publicado sobre essa experiência.

Por ocasião de serem iniciadas essas experiências, só existia no Estado de São Paulo um estudo experimental sobre a questão de cavalos para citrus. Dispondo de pouco espaço, e ainda menor recurso financeiro, organizara o prof. Filipe W. Cabral de Vasconcelos, em 1930, na Escola Superior de Agricultura de Piracicaba, uma pequena plantação na qual se podia observar o comportamento de 5 diferentes variedades-cavalo para as seguintes variedades-enxerto: Baianinha, Coco e Natal.

As meticulosas observações feitas pelo prof. Vasconcelos, durante todo o período de formação e, posteriormente, através de 7 safras consecutivas, fornecem elementos para interessantes conclusões. Uma publicação sobre esses estudos se acha no prelo, segundo fomos informados.

\section{B) - ESPÉCIES E VARIEDADES EXPERIMENTADAS}

Em agosto de 1933 foram semeadas, em canteiros uniformemente preparados, mil sementes de cada uma das seguintes espécies e variedades que pretendíamos experimentar como cavalo: 
1 - Laranja azeda (C. aurantium L.)

2 - Laranja agro-doce (C. aurantium L. var.)

3 - Laranja caipira ( $C$. sinensis Osbeck var.)

4 - Laranja lima ( $C$. sinensis Osbeck var. lima)

5 - Tangerina cravo (C. nobilis Lour. var. deliciosa Swingle)

6 - Limão cravo (C. aurantifolia Swingle)

7 - Limão rugoso (C. limonia Osbeck var.)

8 - Limão ponderosa (C. limonia Osbeck var.)

9 - Lima da Pérsia (C. auratnifolia Swingle)

10 - Pomelo (C. paradisi Macf. var.)

11 - Cidra (C: medica L.)

12 - Trifoliata (P. trifoliata Raf.)

Os nomes das espécies e variedades citadas estão de acordo com a classificação de Swingle (22), seguida por Hume (8).

Damos, a seguir, rápidas considerações sobre cada uma dessas variedades, a-fim-de esclarecer possiveis confusões sobre a nomenclatura usada.

1 - Laranja azeda : - Tambem conhecida em algumas regiões do Brasil por laranja da terra e laranja amarga, é, em tudo, semelhante à agro-sevilhana, da Espanha, bigarade, da França, arancio amaro, da Itália e sour orange, dos norte-americanos (fig. 1).

Espécie universalmente conhecida como porta-enxerto, constitue o principal cavalo nas plantações do Estado de São Paulo, assim como na Califórnia (e em menor escala noutros centros citrícolas norte-americanos), na Espanha e na Itália. Tem sido empregada tambem nas novas plantações do Rio-de-Janeiro, na Palestina e no Egito (9).

2 - Laranja agro-doce : - Chamam-na tambem amargo-doce, azeda-doce e, nos Estados-Unidos, bitter-sweet. É muito semelhante à laranja azeda (fig. 2), da qual deve provir por cruzamento. $\mathrm{Na}$ literatura sobre citrus poucas referências se encontram sobre essa variedade como cavalo.

Rolfs (19) encontrou várias plantas dessa variedade em MinasGerais e registou o seu fraco desenvolvimento no viveiro.

3 - Laranja caipira : - No Estado de São Paulo dá-se o nome de laranjeira "cạipira" a plantas de $C$. sinensis não enxertadas (seedlings), cujos frutos (fig. 3) são em geral bastante ácidos enquanto imaturos. Completamente maduros, conteem ainda elevada percentagem de açucar, tornando-se de paladar bem apreciavel.

O nome "caipira", portanto, não se aplica a uma e determinada forma, mas sim a várias, o que ocasiona muita confusão. Em algumas 
regiões do Brasil dão o nome de "laranja da China" às laranjeiras provenientes de semente e com os caraterísticos acima apontados.

A maior parte dos primitivos pomares do Estado de São Paulo foi formada sobre esse cavalo.

A-pesar da suscetibilidade às moléstias das raizes e tronco (5), as laranjas doces ( $C$. sinensis) estão sendo cada vez mais empregadas como cavalo em algumas regiões citrícolas, Califórnia, por exemplo.

Isto se tornou possivel depois que foram aperfeiçoados os métodos culturais e bem divulgado o conhecimento dos tratamentos eficientes contra tais moléstias (9).

4 - Laranja lima : - É uma variedade de $C$. sinensis muito espalhada no Brasil, sendo talvez a laranja mais popular entre os brasileiros (fig. 4). Seus frutos quase não teem ácido. Quando bem maduros são dulcíssimos. Em algumas zonas chamam-na serra d'água, nome que deve ser reservado para outra variedade semelhante.

5 - Tangerina cravo : - De pé franco ou enxertada, essa tangerina (fig. 5) tem longa duração e resiste bem às moléstias comuns a $C$. sinensis (podridão do pé, leprose).

A tangerina cravo pode, talvez, representar entre nós o mesmo papel que a Cleopatra (tangerina) vem desempenhando na Flórida como cavalo para certas variedades (24).

6 - Limão cravo : - Tambem chamado no Brasil limão rosa ou francês, é mundialmente conhecido (fig. 6) pelo nome de "rangpur lime." Muito usado como cavalo nas plantações da zona do Rio-deJaneiro, onde as árvores (laranja pera) teem geralmente porte pequeno e limitada duração. Em São Paulo, quando enxertado com a variedade Baía, esse cavalo se tem mostrado muito suscetivel à gomose.

7 - Limão rugoso : - Não se trata do "Florida rough lemon" e sim de um tipo de limão rugoso nacional. Os frutos são, em geral, maiores e teem a casca igualmente rugosa (fig. 7). Não conhecemos pomares comerciais enxertados sobre esse cavalo. É de desenvolvimento muito vigoroso e grande uniformidade na sementeira.

8 - Limão ponderosa : - Espécie bem comum nas coleções cítricas. Tem crescimento rápido, frutos grandes e muitas sementes (fig. 8). Não tem sido ainda utilizado como cavalo em nosso país ou no estrangeiro.

9- Lima da Pérsia : - É a comuníssima lima doce que se encontra distribuida por todo o território nacional (fig. 9). Bem apreciada como cavalo por muitos citricultores do Estado, em virtude de seu rápido desenvolvimento e grande uniformidade na sementeira, é exten- 
samente usada coms cavalo na Palestina (14) onde se tem mostrado muito suscetivel à $X$ yloporose (18). Em São Paulo verificamos o mesmo fato, quando enxertada com a laranja barão $(12,13)$.

10 - Pomelo : - Nossas sementes provieram de uma árvore de pé franco, bastante vigorosa, muito semelhante à pomelo triunfo (fig. 10).

Os pomelos quase não teem sido usados como cavalo nas plantações cítricas em nosso país.

11 - Cidra : - Usamos sementes da conhecida cidra comprida (fig. 11). A cidra só muito raramente é usada como cavalo, por ser muito suscetivel à gomose $(5,9)$.

12 - Trifoliata (fig. 12) : - É cavalo pouco utilizado em nosso país. Muito conhecido como bom porta-enxerto para certas variedades cítricas (Satsuma), bem como para algumas espécies do gênero Fortunella (Kunquats). Resistente ao frio e de porte pequeno, desenvolve-se bem em terrenos frescos, ricos də matéria orgânica (8).

\section{C) - SEMENTEIRA}

Nossa sementeira abrangiaa, como já nos refərimos, 12 variedades pertencentes a 2 gêneros e 8 espécies.

Todas as sementes foram extraidas de frutos recem-colhidos e semeadas ainda úmidas, após lavagem para eliminação da mucilagem aderente.

De cada variedade utilizamos sementes de frutos provenientes de uma única árvore.

O quadro I mostra, na coluna 2, o número de sementes por fruto de cada variedade semeada, fator de certa importância na escolha do cavalo. Sob esse ponto de vista sobressaem-se o limão ponderosa e a cidra com o maior número, ao passo que a lima da Pérsia e as laranjas agro-doce e lima são as mais pobres em sementes.

Quanto à rapidez da germinação, verifica-se (coluna 3) que a cidra e o trifoliata antecedem de alguns dias a maioria das variedades, ao passo que as laranjas doces (lima e caipira) foram as mais tardias, com um retardamento de 14 e 15 dias sobre a cidra.

As colunas 4 e 5 do mesmo quadro I indicam a percentagem de germinação e a frequência da poliembrionia nas variedades experimentadas. Esses dados foram obtidos em outra experiência do nosso plano de trabalhos em colaboração, mas são aquí apresentados em virtude da importância desses fatores no estudo do problema dos cavalos. 


\section{QUADRO I}

$S \odot m \bullet n t e i r a$

\begin{tabular}{|c|c|c|c|c|c|}
\hline CAVALOS & $\begin{array}{c}\text { N.o semen } \\
\text { tes por } \\
\text { fruto }\end{array}$ & $\begin{array}{c}\text { Tempo nec. } \\
\text { p/ germina- } \\
\text { ção (dias) }\end{array}$ & $\begin{array}{l}\% \text { de } \\
\text { gөrmi- } \\
\text { nação }\end{array}$ & $\begin{array}{l}\text { Sementes } \\
\text { poliembri- } \\
\text { ônicas }(\%)\end{array}$ & $\begin{array}{l}\text { Class. por altura } \\
\text { na transplantação } \\
\text { l-mais alta }\end{array}$ \\
\hline 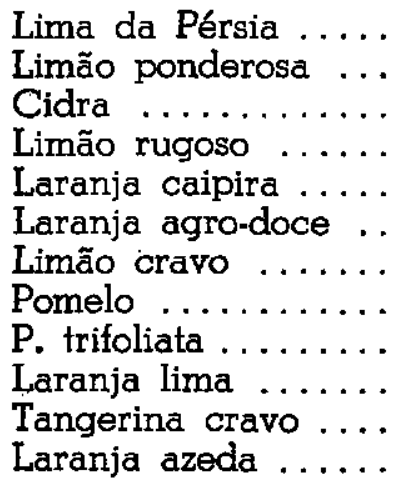 & $\begin{array}{r}6 \\
71 \\
75 \\
16 \\
13 \\
7 \\
12 \\
35 \\
27 \\
8 \\
15 \\
29\end{array}$ & $\begin{array}{l}41 \\
41 \\
38 \\
43 \\
53 \\
43 \\
41 \\
49 \\
39 \\
52 \\
49 \\
41\end{array}$ & $\begin{array}{l}31,40 \\
35,00 \\
30,00 \\
46,60 \\
46,40 \\
30,20 \\
65,00 \\
59,80 \\
\text { não dete } \\
\text { não dete } \\
\text { não dete } \\
44,20\end{array}$ & \begin{tabular}{|c}
10,83 \\
0,0 \\
0,67 \\
16,74 \\
24,14 \\
16,56 \\
8,31 \\
25,08 \\
erminada \\
erminada \\
orminada \\
0,0
\end{tabular} & $\begin{array}{rr} & 1 \\
& 2 \\
3 \\
4 \\
4 \\
5 \\
6 \\
7 \\
\\
\\
\quad 8 \\
9 \\
\quad 10 \\
\quad \quad 11 \\
12\end{array}$ \\
\hline
\end{tabular}

Como demonstrou Webber (25), a poliembrionia é um grande auxiliar na seleção de cavalos para enxertia, uma vez que só um dos embriões provem de origem sexual e os demais, sendo apogâmicos, provavelmente (2) reproduzem, na íntegra, os caracteres da planta-mãe.

Sabe-se tambem que o número de sementes poliembriônicas, bem como o número de embriões de cada semente varia de uma planta para outra, dentro da mesma espécie e variedade. Traub (23) conseguiu, mesmo, por meio da variação na nutrição dos frutos, reduzir a intensidade desse fenômeno nas sementes de uma mesma planta.

Entretanto, em nossas experiências nem sempre temos observado a esperada relação entre a percentagem de poliembrionia e a uniformidade das plantas na sementeira. O pomelo, còm $25,08 \%$ de sementes poliembriônicas, apresentou maior desuniformidade que o limão cravo, com apenas $8,31 \%$ (quadro I).

O tamanho das plantas no primeiro períado de desenvolvimento (sementeira e viveiro) nem sompre nos dá idéia exata do seu desenvolvimento futuro. Webber (25), trabalhando com laranja azeda, estabeleceu correlação entre o porte das plantas de viveiro e sua produção As mudas maiores deram origem a árvores maiores e mais produtivas, enquanto as mudas menores originaram árvores menores memos produtivas. Mendel (11), experimentando com a lima doce, chegou a resultado bem diverso, porquanto, ao fim de pouco tempo, todas as diferenças existentes entre as plantas (com exceção das "variantes"') desapareceram. 
A discordância entre os resultados destas experiências demonstra que não podemos generalizar observações feitas sobre uma dada espécie, com relação ao valor das plantas, considerando apenas a primeira fase de crescimento. É preciso sempre levar em conta a tendência para variação demonstrada pelo material em exame.

No caso particular dos citrus, esta tendência deve estar em correlação com a faculdade de uma dada planta produzir maior ou menor percentagem de embriões apogâmicos.

A nossa sementeira, que foi sempre tratada da maneira mais uniforme possivel, apresentava, por ocasião da transplantação, o desenvolvimento relativo das 12 variedades, conforme se vê na coluna 6 do quadro I.

Como se verá mais adiante (quadros II e IV), algumas variedades, como as laranjas azeda e lima, que tiveram pequeno desenvolvimento na sementeira, melhoraram bem a sua posição quando transplantadas para o viveiro e enxertadas.

\section{D) - VIVEIRO}

Após 6 meses de sementeira, em fevereiro de 1934, foram transplantadas para o viveiro, num só dia, 122 plantas de cada cavalo, tendo-se - cuidado de escolher as plantinhas mais desenvolvidas, de maneira a constituirem um grupo bem homogêneo, conforme recomenda Webber (25).

As plantas de cada cavalo ficaram em uma só linha, como se pode ver no gráfico 1 .

Objetivando observações posteriores à enxertią, transplantamos mais 1 d mudas de cada cavalo empregado em uma só linha, as quais permaneceram em viveiro, sem ser enxertadas, até a ocasião da plantação definitiva (gráfico 1).

Ao passarem da sementeira para o viveiro, todas as plantas foram podadas nas copas e raizes, conservando-se estas $\mathrm{com} 25 \mathrm{~cm}$ e aquelas com $30 \mathrm{~cm}$.

Em julho de 1934 fez-se a primeira medição de altura, no viveiro, obtendq-se os dados da coluna 2 do quadro II. Nessa ocasião as maiores alturas médias haviam sido atingidas pelo limẩo rugoso $(72,8 \mathrm{~cm})$, lima da Pérsia $(71,2 \mathrm{~cm})$ e limão cravo $(67,8 \mathrm{~cm})$; a laranja lima $(34,2 \mathrm{~cm})$ 
e o trifoliata $(35,2 \mathrm{~cm}$ ) eram as menores, ao passo que a laranja ažeda $(50,0 \mathrm{~cm})$ ocupava posição média entre esses extremos.

Havia uma grande uniformidade entre os cavalos do limão rugoso, da lima da Pérsia, do limão cravo, das laranjas azeda e agro-doce e do trifoliata. Os restantes cavalos apresentavam certa desuniformidade, que era máxima no limão ponderosa.

As laranjas doces (caipira e lima), o pomelo, a cidra e o limão cravo mostravam tendência para maiör desenvolvimento lateral, emitindo muitos galhos, ao passo que as laranjas azeda e agro-doce, a tangerina cravo, o limão rugoso, o trifoliata e a lima da Pérsia se desenvolviam eretos.

Em nova medição de altura, feita em dezembro de 1934, obtivemos os dados da coluna 3 (quadro II). Os 3 cavalos de mais rápido crescimento (limão rugoso, limão cravo e lima da Pérsia) continuaram mantendo-se na vanguarda, mas já se notavam algumas alterações extraordinárias, bem evidentes nas colunas 4 e 5 do mesmo quadro II. Enquanto o limão rugoso e a lima da Pérsia tiveram um aumento de $23,4 \mathrm{~cm}$ e $26,8 \mathrm{~cm}$, respectivamente, o trifoliata e a agro-doce aumentaram 41,6 $\mathrm{cm}$ e $37,8 \mathrm{~cm}$.

\section{QUADRO II}

\section{Altura média dos cavalos (cm)}

\begin{tabular}{|c|c|c|c|c|c|c|c|}
\hline \multirow{2}{*}{ CAVALOS } & \multicolumn{2}{|c|}{1934} & \multicolumn{2}{|c|}{ Aum. em 6 meses } & \multirow{2}{*}{$\begin{array}{l}1936 \\
\text { Julho }\end{array}$} & \multicolumn{2}{|c|}{ Aum. em 2 anos } \\
\hline & Julho & Dezbr. & $\begin{array}{r}\text { Total } \\
\text { (cm) }\end{array}$ & $\begin{array}{c}\text { Relativo } \\
(\%)\end{array}$ & & $\begin{array}{r}\text { Total } \\
\text { (cm) }\end{array}$ & $\begin{array}{c}\text { Relativo } \\
(\%)\end{array}$ \\
\hline Laranja lima. . . . . . . & 34,2 & 63,0 & 28,8 & 84,2 & 125,0 & 90,8 & 265,4 \\
\hline P. trifoliata . . . . . & 35,2 & 76,8 & 41,6 & 118,1 & 142,5 & 107,3 & 304,8 \\
\hline Pomelo. ...... & 39,3 & 74,5 & 35,2 & 89,5 & 136,7 & 97,4 & 247,8 \\
\hline Laranja cajpira . . . & 41,8 & 64,5 & 22,7 & 54,3 & 157,5 & 115,7 & 276,7 \\
\hline Tangerina cravo .... & 49,8 & 72,8 & 23,0 & 46,1 & 121,5 & 71,7 & 134,9 \\
\hline Laranja azeda . . . . . & 50,0 & 76,5 & 26,5 & 53,0 & 184,5 & 134,5 & 269,0 \\
\hline Laranja agro-doce. . & 56,6 & 94,4 & 37,8 & 66,7 & 164,0 & 107,4 & 189,7 \\
\hline Cidra .......... & 56,9 & 89,6 & 32,7 & 57,4 & 235,5 & 178,6 & 313,8 \\
\hline Limão ponderosa . . & 60,0 & 88,8 & 28,8 & 48,0 & 224,0 & 164,0 & 273,3 \\
\hline Limão cravo ..... & 67,8 & 103,0 & 35,2 & 51,9 & 212,5 & 144,7 & 213,4 \\
\hline Lima da Pérsia & 71,2 & 98,0 & 26,8 & 37,6 & 222,5 & 151,3 & 212,5 \\
\hline Limão rugoso . . . . & 72,8 & 96,2 & 23,4 & 32,1 & 239,5 & 166,7 & 228,9 \\
\hline
\end{tabular}


Pela coluna 5 (aumento relativo) verifica-se que o trifoliata (um dos menores em julho) aumentou $118,1 \%$ na altura. Aumentos rápidos tambem tiveram o pomelo $(89,5 \%)$ e a laranja lima $(84,2 \%)$, ao passo que os cavalos maiores na medição de julho (limão rugoso, lima da Pérsia) tiveram os mais baixos aumentos relativos " $(32,1 \%$ e $37,6 \%)$.

É bém clara a tendência de nivelamento verificada ao fim de um ano de viveiro entre as espécies e variedades de cavalos ensaiados.

Na coluna 6 vamos encontrar a altura dos cavalos (não enxertados) dois anos depois da primeira medição; nas colunas 7 e 8 estão registados os aumentos total e relativo nesse mesmo período.

A cidra, os limões rugoso, ponderosa e cravo e a lima da Pérsia tiveram os maiores aumentos totais, enquanto a tangerina cravo continuou muito vagarosa. Nesse período a laranja azeda sobrepujou a agrodoce, tanto em crescimento total como relativo.

Os maiores aumentos relativos, entretanto, se verificaram com os cavalos de cidra $(313,8 \%)$ e trifoliata $(304,8 \%)$.

Cabe aquí registar que, por várias vezes, a verrugose (Elsinoë fawcetti Bit. e Jenkins) irrompeu nas folhas das laranjas azeda e agro-doce e do limão cravo, sendo prontamente combatida. As demais variedades experimentadas demonstraram boa resistência ao ataque da moléstia no período considerado.

Outras moléstias não foram verificadas nesse período.

Enxertia : - Sendo nosso intento experimentar o comportamento dos 12 cavalos em estudo com as nossas principais variedades comerciais (Baianinha, Pera e pomelo Marsh-seedless), enxertamos 40 plantas de cada cavalo com borbulhas de cada uma dessas 3 variedades (gráfico 1). A enxertia foi realizada em fevereiro de 1935. Utilizaramse borbulhas de uma única árvore matriz de cada variedade-enxerto.

A altura da enxertia, uniforme para todas as plantas, foi de $30 \mathrm{~cm}$ do solo.

Para se ter uma idéia do vigor demonstrado pela brotação do enxerto, damos, no quadro III, a altura média atingida no primeiro período de crescimento.

É evidente a tendência para ananismo imprimida pelo cavalo de trifoliata às 3 variedades-enxerto; tendência oposta mostram os cavalos de lima da Pérsia e limão cravo. 


\section{QUADRO III}

Altura média atingida com o primeiro crescimento do enxerto $(\mathrm{cm})$

\begin{tabular}{|c|c|c|c|}
\hline : CAVALOS & $\begin{array}{l}\text { Laranja } \\
\text { Baianinha }\end{array}$ & $\begin{array}{c}\text { Laranja } \\
\text { Pera }\end{array}$ & $\begin{array}{c}\text { Pomelo } \\
\text { Marsh-seedless }\end{array}$ \\
\hline 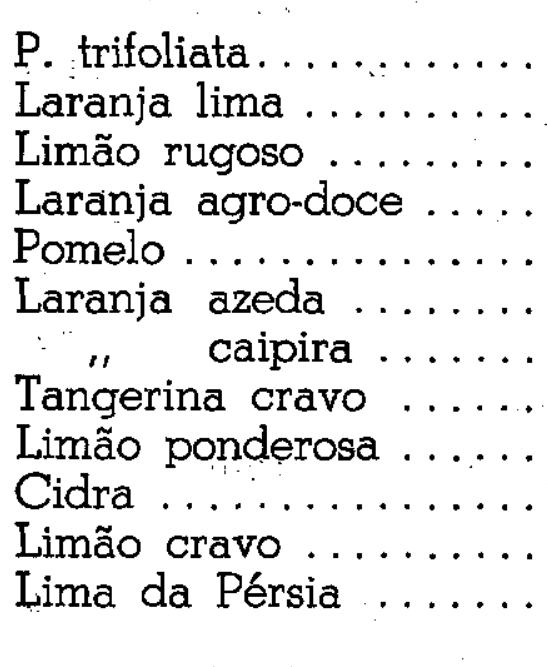 & $\begin{array}{r}37,0 \\
48,8 \\
51,0 \\
52,0 \\
53,4 \\
54,0 \\
55,4 \\
58,7 \\
63,0 \\
68,0 \\
68,0 \\
71,8\end{array}$ & $\begin{array}{r}33,8 \\
43,0 \\
50,0 \\
50,0 \\
47,0 \\
48,0 \\
45,7 \\
45,7 \\
55,0 \\
55,0 \\
62,0 \\
63,0\end{array}$ & 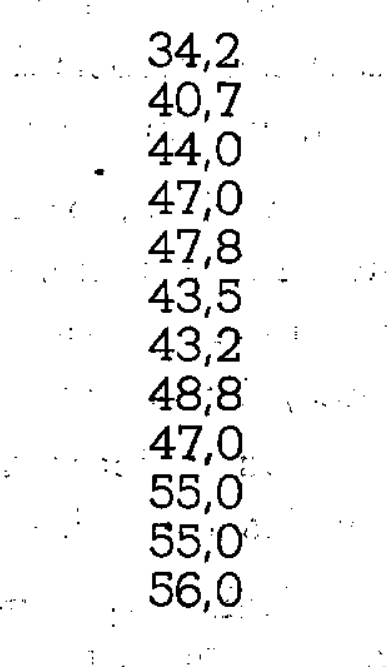 \\
\hline
\end{tabular}

Em julho de 1936 as plantas já estavam em condições de ser transplantadas para o lugar definitivo (pomar), o que só fol felto mais tärde (dezembro), para aguardar estação favoravel.

Naquela data procedemos à medição das circunferências do tronco a 20 e $40 \mathrm{~cm}$ do solo, isto é, abaixo e acima do ponto da enxertia. É sabido que a grossura na base da haste, na laranjeira, é proporcional à altura e volume da copa (25). Os dados obtidos constam nos quadros IV e $\mathrm{V}$ : e mostram claramente que as kariedades de rápido crescimento (lima da Pérsia, limões cravo, rugoso e ponderosa, e cidra) produziram mudas maiores.. Da mesma forma, espécies e variedades de crescimento lento (trifoliata, pomelo, laranjas caipira e lima, tangerina cravo) produziram mudas menores, enquanto as laranjas azeda e agro-doce produziram mudas médias.

Utilizando-se dos dados obtidos para organização dos quadros IV $e \mathrm{~V}$, foram calculados os dados do quadro VI, que apresenta um teste "entre-dentro" cavalos. Vê-se pelos valores de $\vartheta$ (coluna 5) que as espécies e variedades de cavalo experimentadas se comportam de thaneira muito diferente entre si (com significância bem fora de $1 \%$ \%imité) em relação ao desenvolvimento durante à formação das mudas (víveiro): 


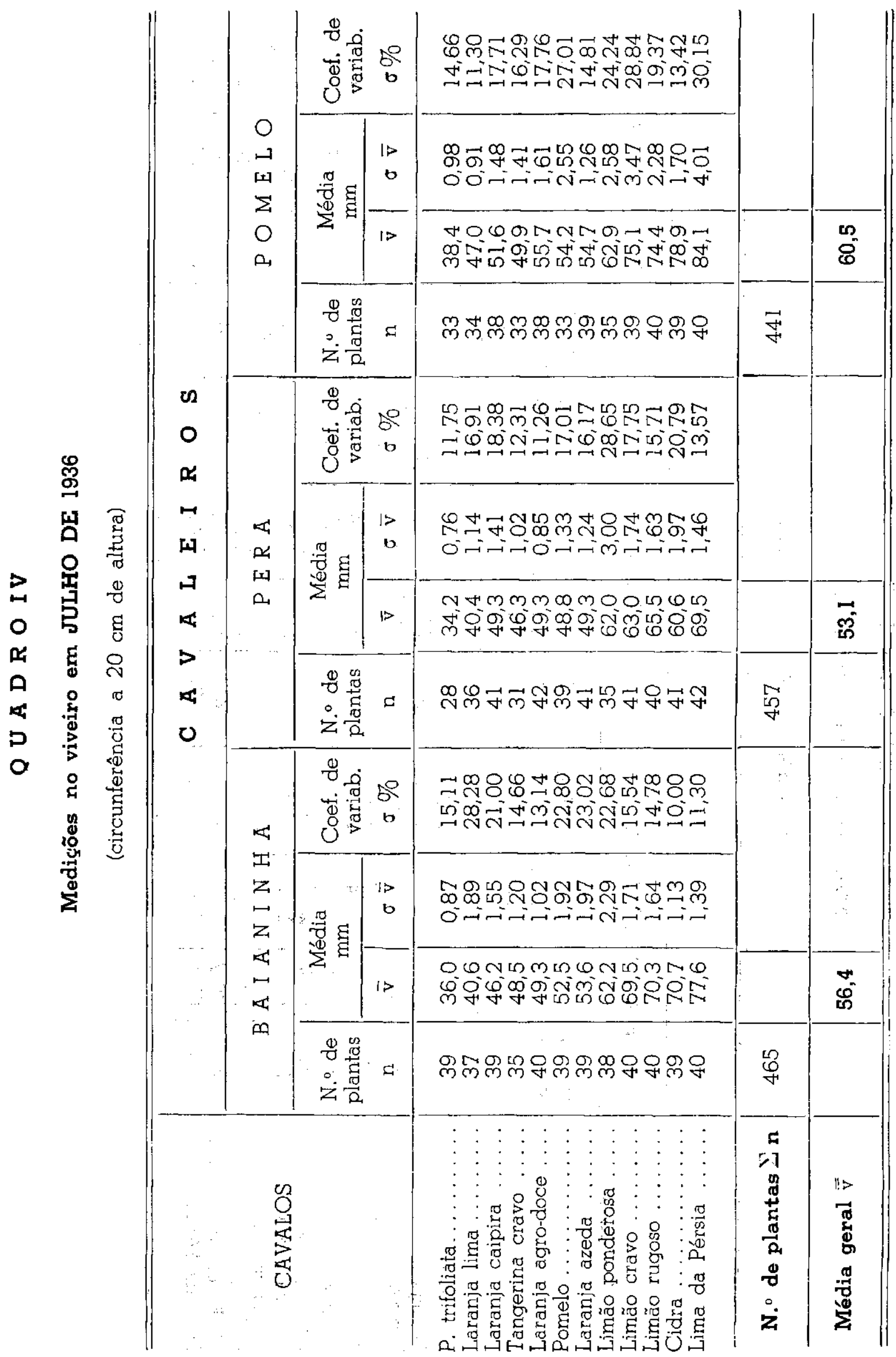




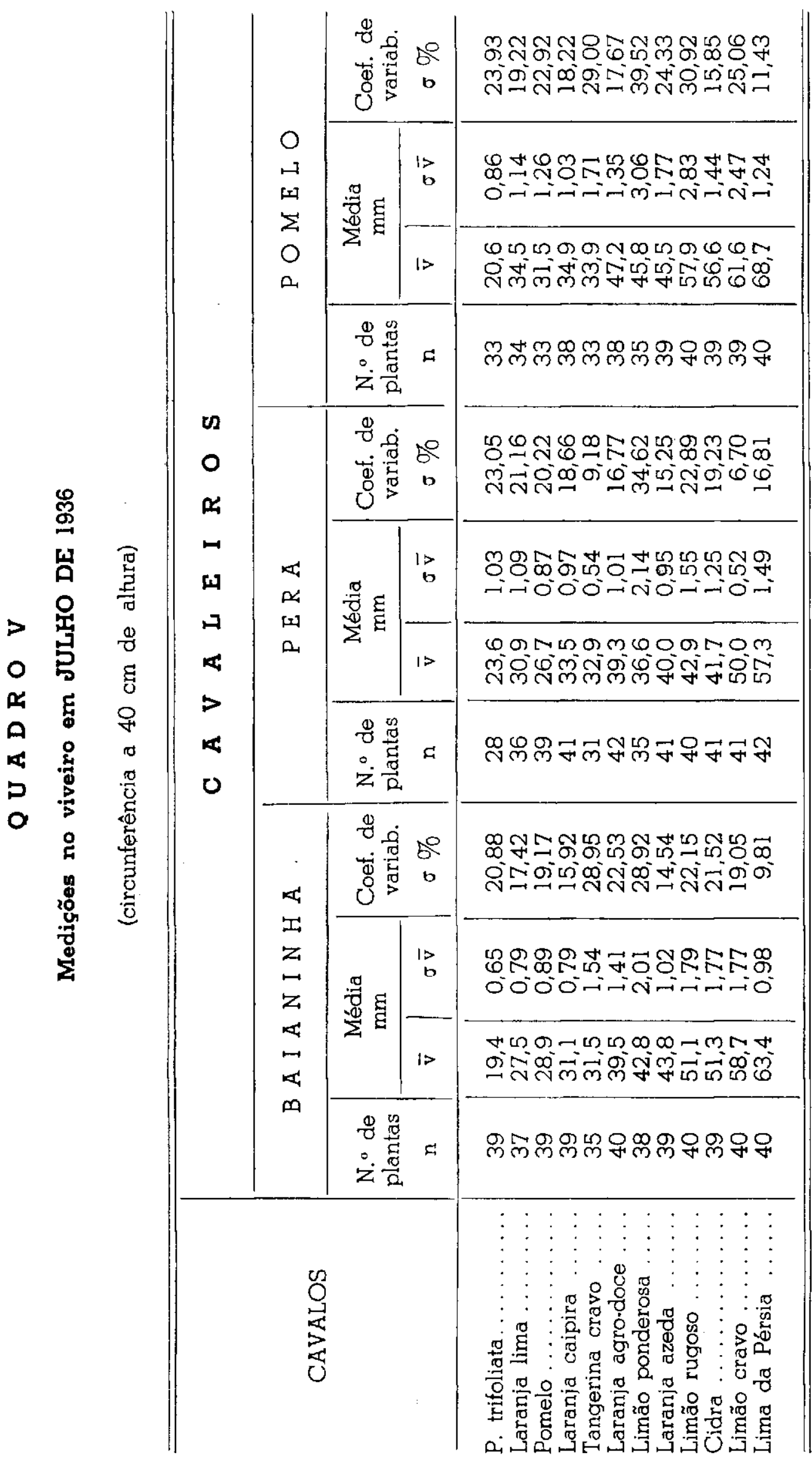




\section{QUADRO VI}

Variação da circunferência dos cavalos a 20 e $40 \mathrm{~cm}$

\begin{tabular}{|c|c|c|c|c|}
\hline \multirow{2}{*}{$\begin{array}{c}\text { Decomposição } \\
\text { do Erro }\end{array}$} & Erro total & $\begin{array}{l}\text { Erro entre } \\
\text { cavalo }\end{array}$ & $\begin{array}{l}\text { Erro dentro } \\
\text { cavalo }\end{array}$ & $\vartheta$ \\
\hline & $\begin{array}{c}\sigma \mathrm{T} \\
\mathrm{nf}=464\end{array}$ & $\begin{array}{c}\sigma E \\
n f=11\end{array}$ & $\begin{array}{c}\sigma D \\
\mathrm{nf}=453\end{array}$ & $\frac{\sigma E}{\sigma D}$ \\
\hline Baianinha $(20 \mathrm{~cm})$ & 16,05 & 82,29 & 9,97 & 8,25 \\
\hline Baianinha $(40 \mathrm{~cm})$ & 15,35 & 83,50 & 8,49 & 9,83 \\
\hline Pera $(20 \mathrm{~cm}) \ldots$ & 13,92 & 64,50 & 9,78 & $\underline{6,59}$ \\
\hline Pera $(40 \mathrm{~cm}) \ldots$ & 12,08 & 64,84 & 7,41 & 8,75 \\
\hline Pomelo $(20 \mathrm{~cm})$. & 19,44 & 86,93 & 13,93 & 6,24 \\
\hline Pomelo $(40 \mathrm{~cm})$. & 17,33 & 84,33 & 11,21 & 7,52 \\
\hline F6rmulas : & $\sqrt{\frac{\sum_{\mathrm{v} 2}^{n}-\frac{\left(\sum_{v}^{n}\right)^{2}}{n-1}}{n-1}}$ & $\frac{\left(\frac{\sum_{v p}^{n p}}{n p}-\frac{\left(\sum^{n}\right.}{n}\right.}{m-1}$ & $n-m$ & \\
\hline
\end{tabular}

onde: $\mathrm{n}=$ número de plantas

$\mathrm{m}=$ número de cavalos

$\mathrm{np}=$ número de plantas por cavalo

QUADRO VII

Comparação entre as médias para cada variedade-enxerto

(circunferência a $20 \mathrm{~cm}$ )

\begin{tabular}{c|c|c|c|c}
\hline $\begin{array}{c}\text { Variedades } \\
\text { enxerto }\end{array}$ & $\begin{array}{c}\text { N.o de plantas } \\
\mathrm{n}\end{array}$ & $\begin{array}{c}\text { Média } \\
\overline{\mathrm{v}}\end{array}$ & $\begin{array}{c}\text { Erro dentro } \\
\text { cavalos } \\
(\sigma \mathrm{D} \text { quadro VI })\end{array}$ & $\delta=\frac{\overline{\mathrm{v}}_{1}-\overline{\mathrm{v}}_{2}}{\sqrt{\frac{\left(\sigma_{1}\right)^{2}}{\mathrm{n}-1}+\frac{\left(\sigma_{2}\right)^{2}}{\mathrm{n-2}}}}$ \\
\hline \hline POMELO MARSH & 441 & 60,5 & 13,93 & 5,97 \\
BAIANINHA .... & 465 & 56,4 & $\underline{\underline{5,06}}$ \\
PERA .......... & 457 & 53,1 & 9,78 & $\underline{5,07}$ \\
\hline \hline
\end{tabular}


Comparando-se as médias para cada variedade-enxerto (quadro IV), verifica-se um maior desenvolvimento médio dos cavalos, quando enxertados com pomelo Marsh-seedless $(60,5 \mathrm{~mm})$, do que com a Baianinha $(56,4 \mathrm{~mm})$ e a Pera $(53,1 \mathrm{~mm})$. Essas diferenças são tambem significantes (fora de $1 \% 0$ limite), como vemos no quadro VII.

Alem disso, comparando-se a grossura dos troncos das mudas enxertadas (quadro IV) com a dos cavalos não enxertados (quadro VIII, coluna 2), verifica-se que o trifoliata, o pomelo, a lima da Pérsia e, principalmente, a tangerina cravo são beneficamente influenciados pela enxertia com Baianinha, Pera e pomelo Marsh-seedless. A-pesar do retardamento que a poda posterior à enxertia ocasiona, os cavalos citados tinham quase a mesma e, às vezes, até menor grossura do que as mudas enxertadas. A tangerina cravo (pé franco) media $40,4 \mathrm{~mm}$, enquanto enxertada com Baianinha atingia 48,5, com Pera, 46,3 e com pomelo Marsh-seedless, $49,9 \mathrm{~mm}$.

Essas observações estão de pleno acordo com as de. Hodgson e outros (7), feitas nos Estados-Unidos.

Os dados dos quadros IV e $\mathrm{V}$ permitem ainda estabelecer a relação entre a grossura do enxerto (a $40 \mathrm{~cm}$ de altura) e do cavalo (a $20 \mathrm{~cm}$ de altura). Uma tal relação tem certo valor, pois, pode indicar o grau de congenialidade entre cavalo e enxerto $(10,20)$. São conhecidos muitos casos em que o enxerto engrossa mais rapidamente do que o cavalo, e o desequilíbrio assim manifestado causa a morte da planta ("sweet lemon" sobre laranja azeda). Outras vezes, dá-se o contrário: - cavalo engrossa mais rapidamente, havendo uma brusca redução na grossura do tronco, no ponto da enxertia (calamondim sobre limão rugoso).

Pelo quadro IX verifica-se que, 18 meses depois da enxertia, nenhum dos cavalos em estudo era mais fino do que o enxerto, havendo até alguns (pomelo, trifoliata) que apresentavam uma relação enxerto/cavalo um tanto baixa (quase 0,5). As laranjas azeda e agro-doce, a lima da Pérsia e o limão cravo apresentavam as mais altas relações para as três variedades enxertadas.

Sistema radicular desenvolvido no viveiro : - Por ocasião da transplantação das mudas para o lugar definitivo, fizemos fotografar mudas arrancadas de raizes nuas, para ter uma idéia sobre o sistema radicular formado em cada cavalo sob influência das 3 variedadesenxerto. Além disso, fotografamos tambem mudas arrancadas dentre cavalos não enxertados.

As figuras 13 e 14 mostram as raizes das doze espécies-variedadescavalo, em mudas não enxertadas. 


\title{
QUADRO VIII
}

\section{Cavalos não enxertados}

Circunferência do tronco

Médias das medições em julho de 1936

\begin{tabular}{|c|c|c|}
\hline ALTURA DAS MEDIĢÕES & $\begin{array}{c}20 \mathrm{~cm} \\
\mathrm{~mm}\end{array}$ & $\begin{array}{c}40 \mathrm{~cm} \\
\mathrm{~mm}\end{array}$ \\
\hline  & $\begin{array}{l}36,6 \\
40,4 \\
49,1 \\
53,0 \\
56,1 \\
65,8 \\
69,3 \\
78,2 \\
84,5 \\
94,8 \\
100,6 \\
105,9\end{array}$ & $\begin{array}{l}34,6 \\
34,1 \\
39,5 \\
45,8 \\
55,9 \\
56,7 \\
62,9 \\
69,6 \\
78,4 \\
87,3 \\
91,1 \\
98,6\end{array}$ \\
\hline
\end{tabular}

\section{QUADRO IX}

\section{Relação entre a circunferência de}

\author{
"cavaleiro" e "cavalo"
}

Medições em julho de 1936

\begin{tabular}{|c|c|c|c|}
\hline \multirow{2}{*}{$C A V A L O S$} & \multicolumn{3}{|c|}{$C A V A L E I R O S$} \\
\hline & Baianinha & Pera & Pomelo \\
\hline 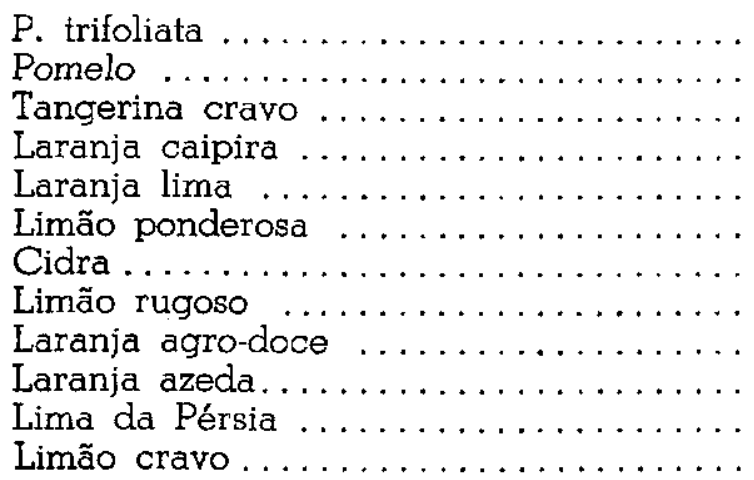 & $\begin{array}{l}0,539 \\
0,550 \\
0,654 \\
0,673 \\
0,679 \\
0,688 \\
0,725 \\
0,727 \\
0,801 \\
0,817 \\
0,826 \\
0,845\end{array}$ & $\begin{array}{l}0,690 \\
0,547 \\
0,710 \\
0,679 \\
0,765 \\
0,590 \\
0,688 \\
0,655 \\
0,798 \\
0,811 \\
0,819 \\
0,793\end{array}$ & $\begin{array}{l}0,537 \\
0,581 \\
0,695 \\
0,676 \\
0,734 \\
0,728 \\
0,717 \\
0,788 \\
0,847 \\
0,832 \\
0,817 \\
0,820\end{array}$ \\
\hline
\end{tabular}


Nas figuras 15 e 16 vemos as raizes das mesmas doze espéciesvariedades-cavalo, em mudas enxertadas com laranja Baianinha; as tiguras 17 e 18 são de mudas enxertadas com laranja Pera; as figuras 19 e 20 são de mudas enxertadas com pomelo Marsh-seedless.

Ao primeiro exame, ressalta a pobreza do sistema radicular da cidra, tanto de pé franco como enxertada com qualquer das 3 variedadesenxerto. Falta uma raiz principal (pião) e há "quase ausência absoluta de raizes fibrosas finas. Como veremos mais adiante, esse defeito tem influência direta sobre o pegamento das mudas por ccasião da transplantação.

Os limões cravo e ponderosa e o pomelo apresentam tambem, embora em menor grau, esses defeitos.

Os demais cavalos mostram bom e abundante sistema radicular, algumas vezes até em contraste com o fraco desenvolvimento da copa (tangerina cravo).

\section{E) - INSTALAÇÃO DEFINITIVA DOS ENSAIOS}

Em dezembro de 1936 fez-se a instalação definitiva dos ensaios, transplantando-se as mudas de raizes nuas, com poda parcial da copa, para seis quadras e obedecendo às indicações que se seguem:

1) Dividiu-se o ensaio em três partes, correspondendo cada parte a uma variedade de enxerto, isto é:
a) Laranja Baianinha
b) Laranja Pera
c) Pomelo Marsh-seedless.

2) Com relação aos cavalos, em virtude do número reduzido de plantas uniformes que obtivéramos de algumas variedades, fizemos a divisão em dois grupos:

Grupo A - Constituido pelos seis cavalos que mais interesse despertam: laranjas azeda, agro-doce e caipira; limões cravo e rugoso e lima da Pérsia.

Grupo B - Constituido pelos seis cavalos restantes: laranja lima, tangerina cravo, limão ponderosa, pomelo, cidra e trifoliata.

3) De cada representante do grupo $\boldsymbol{A}$ foram transplantadas 36 plantas, distribuidas em 4 parcelas de 9 plantas, repetindo-se isso para cada variedade-enxerto.

4) De cada representante do grupo $B$ foram transplantadas 16 plantas, distribuidas em 4 parcelas de 4 plantas, repetindo-se isso para cada variedade-enxerto. 
5) $O$ compasso da plantação foi igual em todas as quadras : $8 \times 8$ metros ou 64 metros quadrados por planta.

6) Obtivemos, assim, seis quadras que foram envolvidas por uma linha isolante de plantas da mesma variedade ou espécie que aquelas da quadra envolvida (gráfico 2). Todas as plantas isolantes foram enxertadas sobre cavalo de laranja azeda.

7) Cada quadra ficou com 24 parcelas e foi dividida (duas direções, ângulos retos) em 4 blocos de 6 parcelas.

8) A distribuição das diferentes variedades-cavalo pelas parcelas de cada bloco foi feita ao acaso, conforme recomendam Fisher e Wishart (6), ficando como demonstram os gráficos 3 a 5 .

9) Para continuar o estudo de confronto entre os cavalos enxertados e os de pé franco (seedlings), transplantamos para uma sétima quadra 8 plantas de cada variedade-cavalo, ficando dispostas conforme - gráfico 6.

\section{F) - INFORMAÇÕES GERAIS SOBRE O SOLO}

Os solos da Estação Experimental de Limeira, onde se acham localizados estes ensaios, foram estudados por Paiva Neto (16).

\section{G) - PEGAMENTO DAS MUDAS NA TRANSPLANTAÇÃO}

Ao fazermos a transplantação das mudas para o pomar, pudemos verificar que o cavalo de cidra se comporta muito mal durante essa operação. A-pesar dos cuidados dispensados às plantas, fomos obrigados a proceder a diversas replantas, por não pegarem as mudas, mesmo quando transplantadas com torrão. E isso aconteceu com todas três variedades-enxerto.

Esse fato surpreendeu-nos, porquanto todos os demais cavalos mostraram comportamento completamente diferente, com um pegamento de $100 \%$. A única explicação plausivel foi, como já notamos atrás, a de que o sistema radicular da cidra é quase desprovido de ramificações laterais finas, as quais muito contribuem para facilitar a nutrição da planta em o novo meio em que vai viver.

Algumas plantas sobre o limão ponderosa tiveram a brotação muito retardada, o que indica tambem certa deficiência de adaptação a essa operação.

\section{Agradecimentos}

Agradecemos ao prof. F. G. Brieger, pela orientação nos cálculos e leitura do manuscrito. 


\section{R E S U M O}

1 - A presente contribuição refere-se aos trabalhos iniciais para o estabelecimento, na Estação Experimental de Limeira, de experiências sobre cavalos para as principais variedades cítricas comerciais no Estado de São Paulo, isto é, as laranjas Baianinha e Pera e o pomelo Marsh-seedless.

2 - Nessas experiências estão em estudo 12 variedades-cavalo pertencentes a 2 gêneros e 8 espécies.

3 - Ligeiras referências são feitas sobre as 12 espécies e variedades-cavalo, algumas das quais ainda não foram utilizadas no Estado, para tal fim.

4 - Citam-se dados sobre o número de sementes, germinação, poliembrionia e desenvolvimento relativo na sementeira.

5 - O desenvolvimento no viveiro, antes e depois da enxertia, se baseia em medições feitas de tempos a tempos, a princípio nos cavalos (altura) e depois nos cavalos e enxertos (circunferências da haste).

6 - As últimas medições feitas no viveiro, mostram que há comportamento significantemente diferente entre as 12 espécies e variedades-cavalo experimentadas, considerando-se os seus respectivos desenvolvimentos.

7 - No viveiro sobressairam, por mais rápido crescimento, as seguintes espécies e variedades-cavalo: lima da Pérsia, limão rugoso, limão cravo, limão ponderosa e cidra.

O trifoliata, as laranjas lima e caipira, e a tangerina cravo foram de crescimento mais lento, enquanto as laranjas azeda e agro-doce e o pomelo ocuparam posição média.

8 - Instalou-se a experiência definitiva com a transplantação das mudas, em 1936, para o lugar definitivo (pomar), formando-se 6 quadras (4 blocos e 24 parcelas cada uma).

9 - O plano destas experiências comporta observações sobre:

a) Desenvolvimento das plantas

b) Produção (frutos) qualitativa e quantitativa

c) Suscetibilidade a moléstias e pragas

d) Interação entre cavalos e enxertos

e) Longevidade das plàntas.

\section{S U M M A R Y}

1 - The present paper deals with the first results of an extensive study on the relations between stock and scion in Citrus, in progress at the Experiment Station of Limeira, of the Instituto Agronômico of Campinas, São Paulo, Brazil, since 1933.

2 - All the scions used belong to three commercial varieties : Baianinha (orange, derived from "Washington Navel"), Pera (orange, similar to Valencia) and Pomelo (grape-fruit "Marsh-seedless") were collected in each case from one individual of each type.

3 - The following 12 stock were studied:

Laranja azeda (sour orange)

Laranja agro-doce (bitter sweet orange)

Laranja caipira (sweet orange)

Laranja lima (sweet orange)

Tangerina cravo (tangerine)

Limão cravo (Rangpur lime)

Limão rugoso (rough lemon)

Limão ponderosa (ponderosa lèmon) 
Lima da Pérsia (sweet lime)

Pomelo (grape-fruit Triumph)

Cidra (citron)

Trifoliata (Poncirus trifoliata).

All plants obtained came from seeds of one tree of each type, from unprotected flowers however.

4 - Data referring to the number of seeds per fruit, germination, polyembriony and classification according to size are given (quadro I). The mean height of the plants obtained after 6 months and 2 years nursery are to be found in quadro II.

5 - Twelve hundred individuals of each root stock were selected according to their uniform development, in accordance with Webber (25) and on 40 of each buds of the three scions were grafted.

As measure of the development the circumference of the stock at a height of $20 \mathrm{~cm}$ and that of the scion at a height of $40 \mathrm{~cm}$ were used (quadros IV to IX).

6 - An analysis of variance "between" and "within" root stocks (quadro VI) showed in all cases a significant high variation "between" stock. In all cases, the scions were thinner than the stocks (quadro IX), the indices scion-stock varying from ca. 0,5 to 0,8 . The respective means are to be found in quadro IV and V.

7 - There is also a consistent and significant difference between scions as shown by the values in quadro VII.

8 - A comparison between quadro VIII (not budded root stock) and quadro IV (budded) shows that generally the former grow better. They are however some exception to this rule, especially in "Tangerina cravo".

9 - All the observation reported so far were made in the nursery, but the detailed lay-out of the experiment in the orchard is also described. Lots of 4 or 9 plants of each combination were arranged in four complete random replications. The trees supported the planting out very well, only Citron replantings being necessary. The trees are now fully matured and produced already during 3 years. The results of the first five years of the experiment with trees in the orchard, including the analysis of their yields, will be given in a future publication.

\section{I T E R A T U RA C I TA DA}

1. Andrade, E. N. Em Citricultura, pág. 33-37. Tip. Brasil de Rothschild \& Cia. São Paulo, 1929.

2. Brieger, F. G. outros. Estudo sobre o melhoramento da laranja "Baía". III. Bragantia $1: 567-598$ (fig. 1-10-b) 1941.

3. Brieger, F. G. e S. Moreira. Uniformidade da produção numa experiência de adubação na laranjeira Baía. Não publicado ainda.

4. Caryl, R. E. Citrus culture in California. Calif. Agr. Extension Service. Circular 114:1-48. 1940.

5. Fawcett, H. S. Em Citrus diseases and their control, pág. 1-656, 2. a edição, Mc Graw-Hill Book Comp. N. Y. and London, 1936.

6. Fisher, R. A. and J. Wishart. The arrangement of field experiments and the statistical reduction of the results. Imperial Bureau of Soil Science. Technical Communication n. ${ }^{\circ}$ 10:1-24. 1930. 
7. Hodgson, R. W. e outros. Rootstock and scion [influence in citrus. The Cal. Citrograph 23:110. 1937.

8. Hume, H. H. Em The Cultivation of citrus fruits, [pág. 1-561. 1.a edição, The Macmillan Comp. N. Y., 1926.

9. Marloth, R. H. The citrus rootstock problem. Farming South Africa $13: 226-231$. 1938.

10. Mendel, $\mathbf{K}$. The anatomy and histology of the bud-union in citrus. The Palestine Jour. of Botany and Hort. Sci. 1:13-46. 1936.

11. Mendel, K. Seedling size as a criterion for the selection of Sweet Lime stock. Hadar $13: 44-48$ e 81-84, 1940.

12. Moreira, S. Um interessante caso de desharmonia na enxertia de Citrus. Jornal de Agronomia 1:57-62, fig. 1-5. 1938.

13. Moreira, S. Xyloporose. Jornal de Agronomia 1:217-226, fig. 1-10. 1938.

14. Oppenheimer, H. R. A citrus root stock trial on light soil. Hadar 9:3-8. 1936.

15. Oppenheimer, H. R. The stock problem of the Shamouti orange. Hadar 13:245-248. 1940.

16. Paiva Neto, J. E. Notas sobre os solos da Estação Experimental de Limeira. Bragantia 1 : $611-6171941$.

17. Powell, H. C. Em The culture of the orange and allied fruits, pág. 1-355, 1.a edição, Central News Agency, South Africa, 1930.

18. Reichert, I. and J. Perlberger. Xyloporosis - the new citrus diseases. Hadar 20:7-8 1934.

19. Rolfs, P. H. C. Rolfs. Em A muda de citrus. Publ. Secretaria da Agricultura, Belo-Horizonte, Minas-Gerais, pág. 1-126. 1931.

20. Ruggiere, G. Ricerche sul'affinitá d'innesto de limone "Monachello" con altri citri. Bul. della R. Stazione de Path. Vegetal. Firenze-Itália, pág. 1-11. 1937.

21. Setzer, Jos6. As caraterísticas dos principais solos do Estado de São Paulo. Bragantia $1: 255-359$. 1941.

22. Swingle, W. T. Citrus. Em Bailey, L. H. - Standard Cyclopedia of Hort. 3:780785. New Ed. 1933. The Macmillan Comp. New York.

23. Traub, H. P. Artificial control of nucellar embryony in citrus. Science n. s. 83;165-166. 1936.

24. Vosbury, E. D. Culture of citrus fruits in the Gulf States. U. S. Dept. Agric. Famers'Bulletin 1343:1-20. 1929.

25. Webber, H. J. Variations in citrus seedlings and their relation to rootstock selection. Hilgardia 7:1-79. 1932.

26. Wright, C. A formação do pomar de citrus. Circ. Serviço de Citricultura do Estado de São Paulo 5:19-21. 1934. 


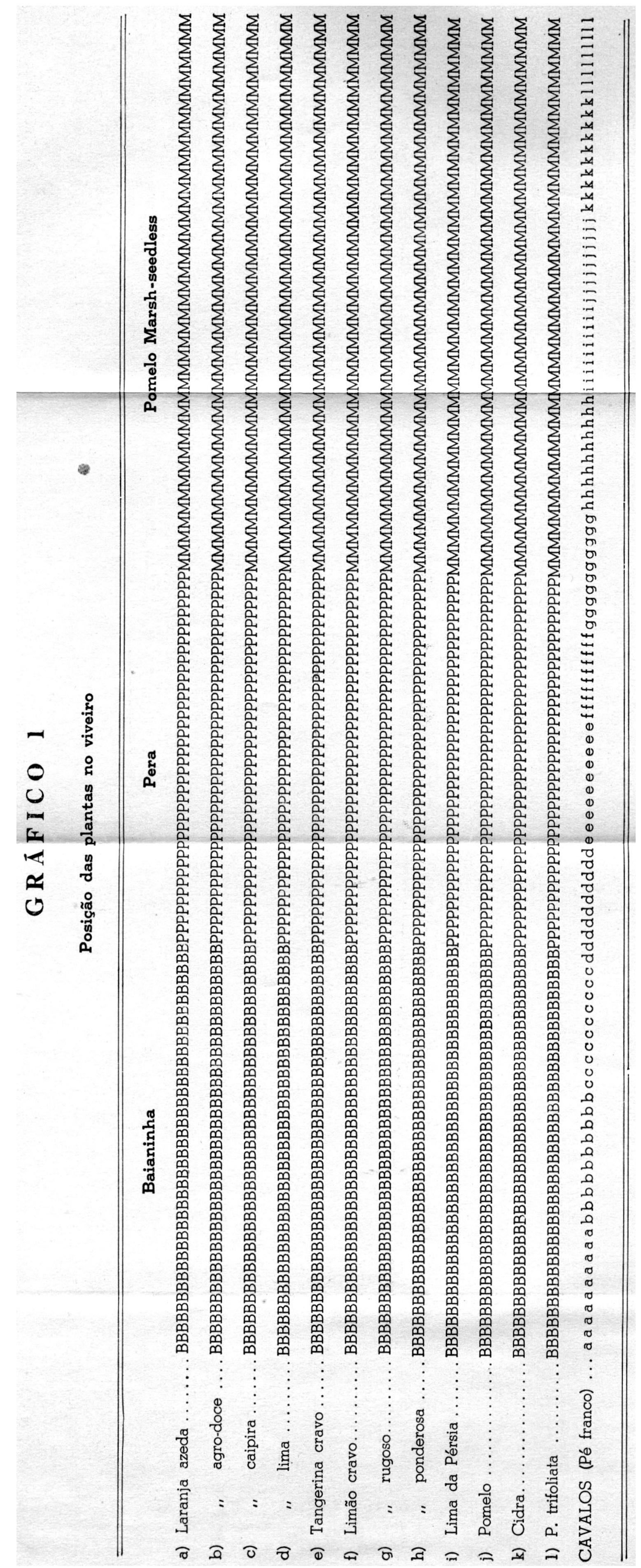




\section{ESTACȦO EXPERIMENTAL DE LIMEIRA ENSAIO COMPARATIVO DE CAVALOS



baianinha Puracicaba

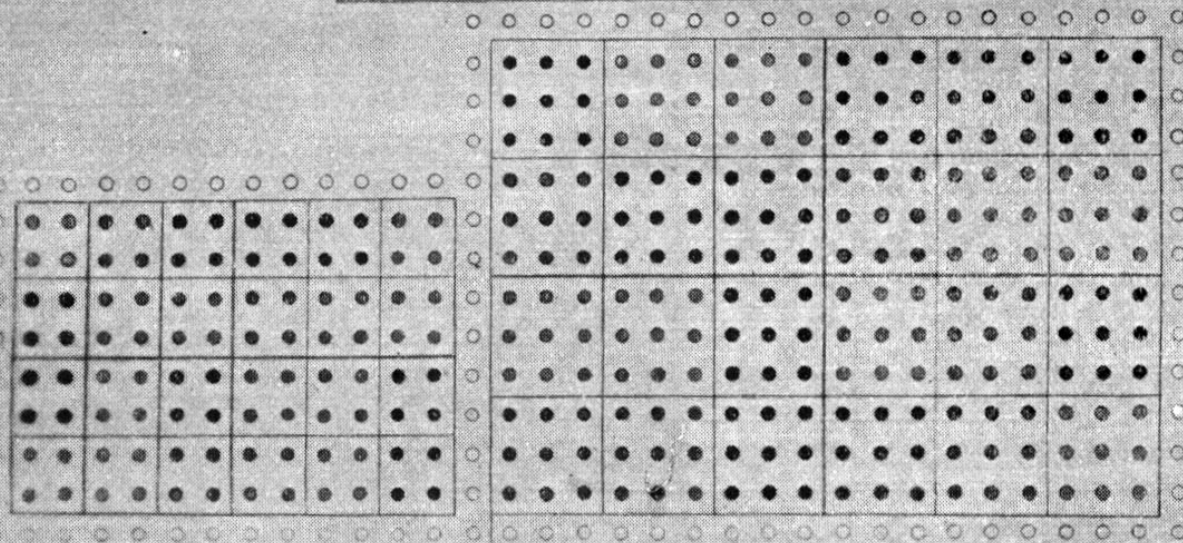

\section{laranja Pera}
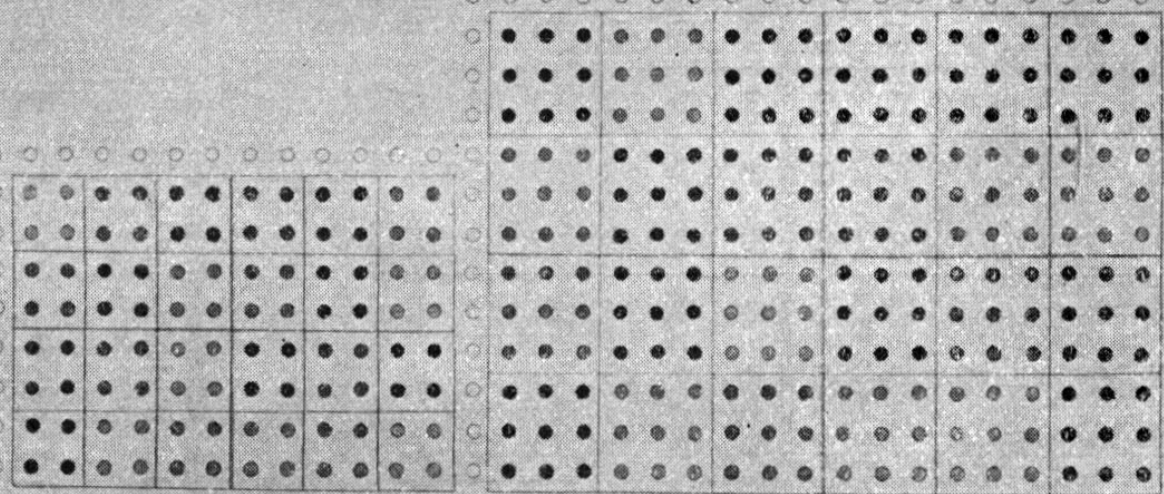

\section{POMelo MARsh SeEdLesS}

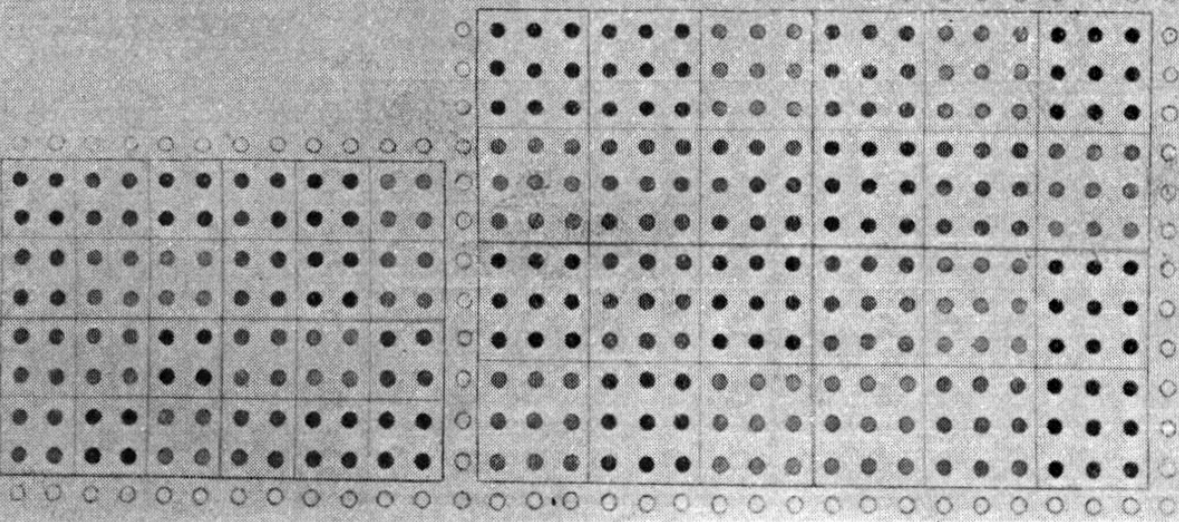

Gráfico 2 - Representação das Quadras, Blocos e Parcelas. 


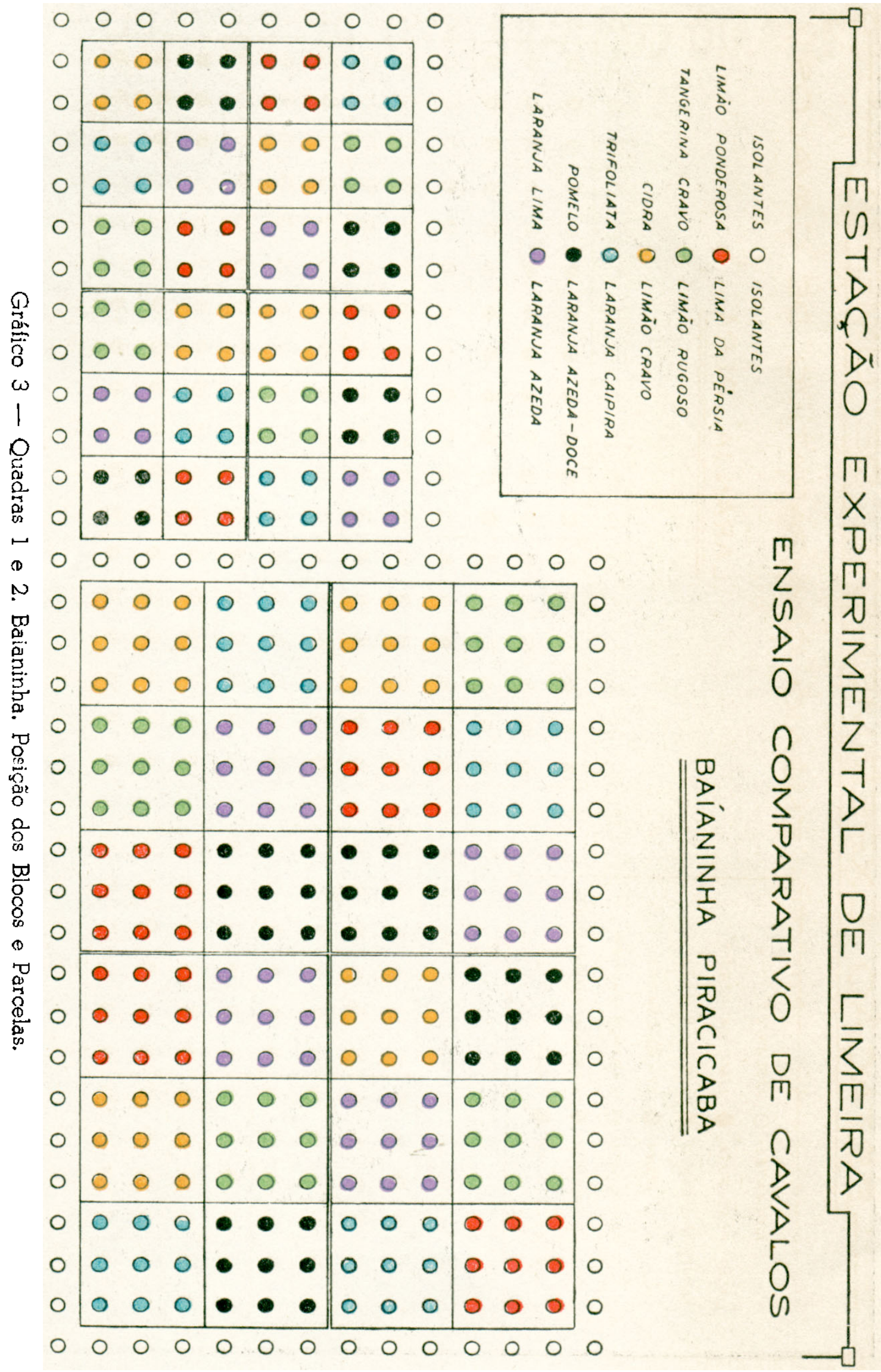









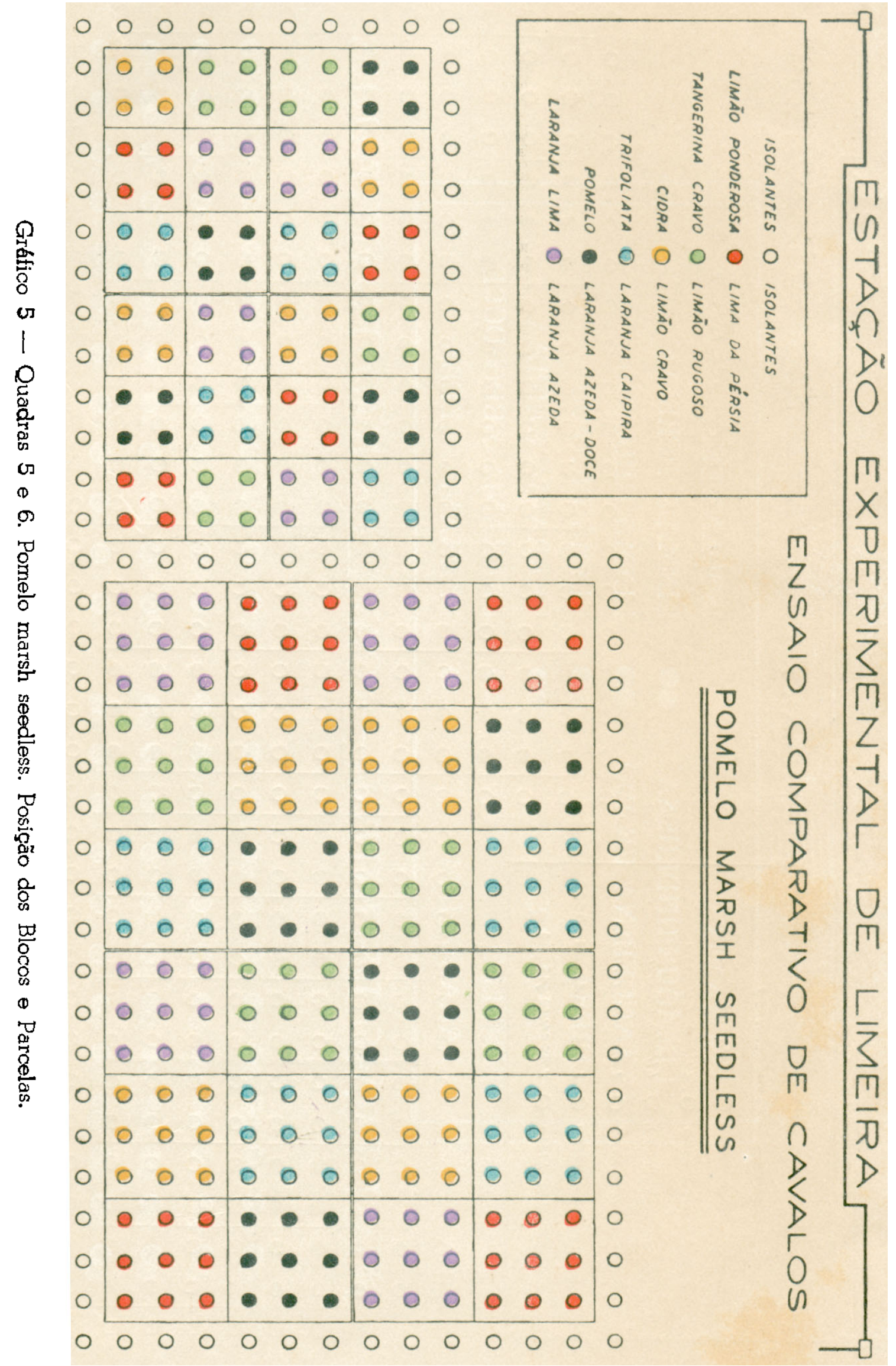




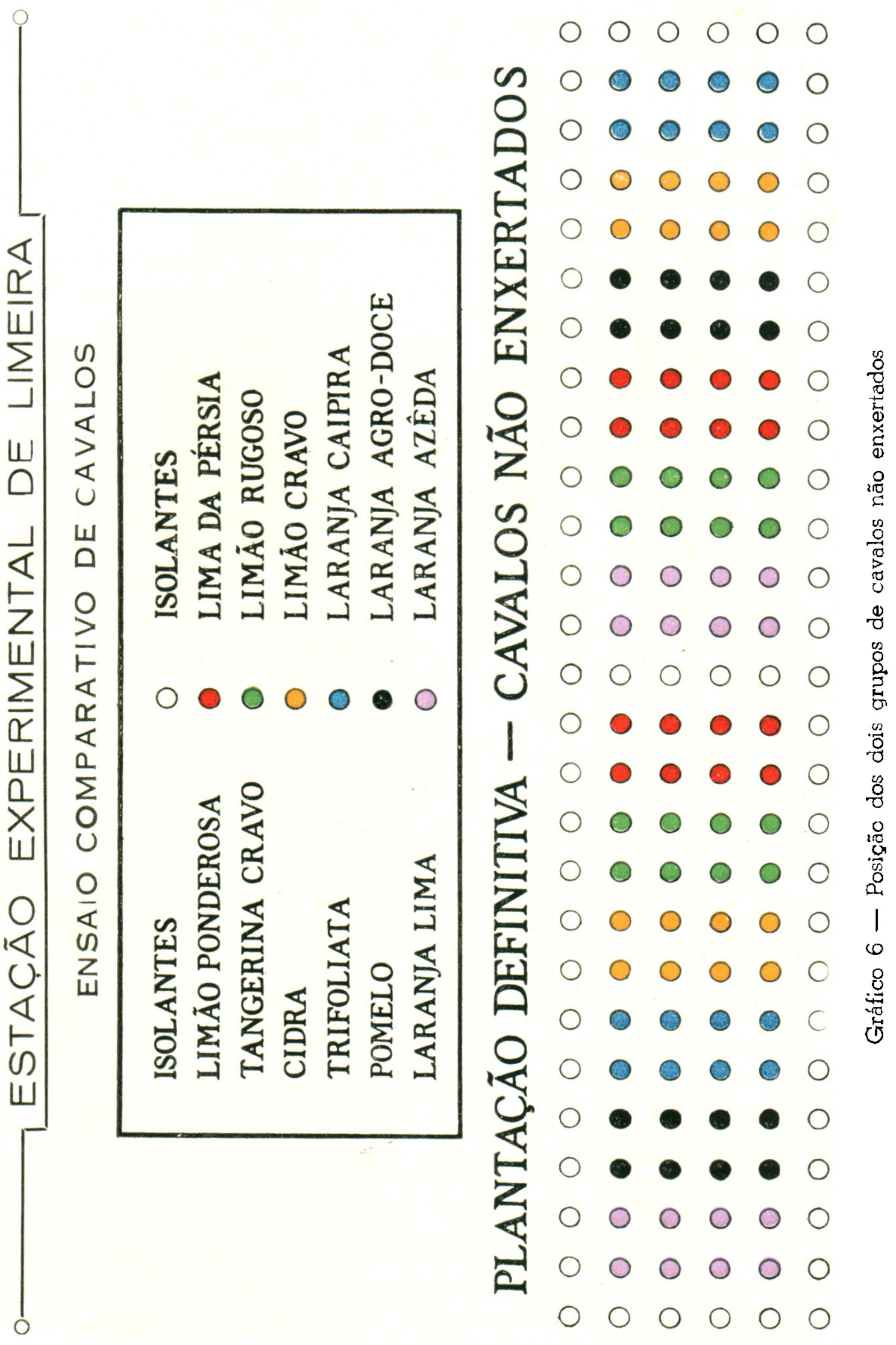




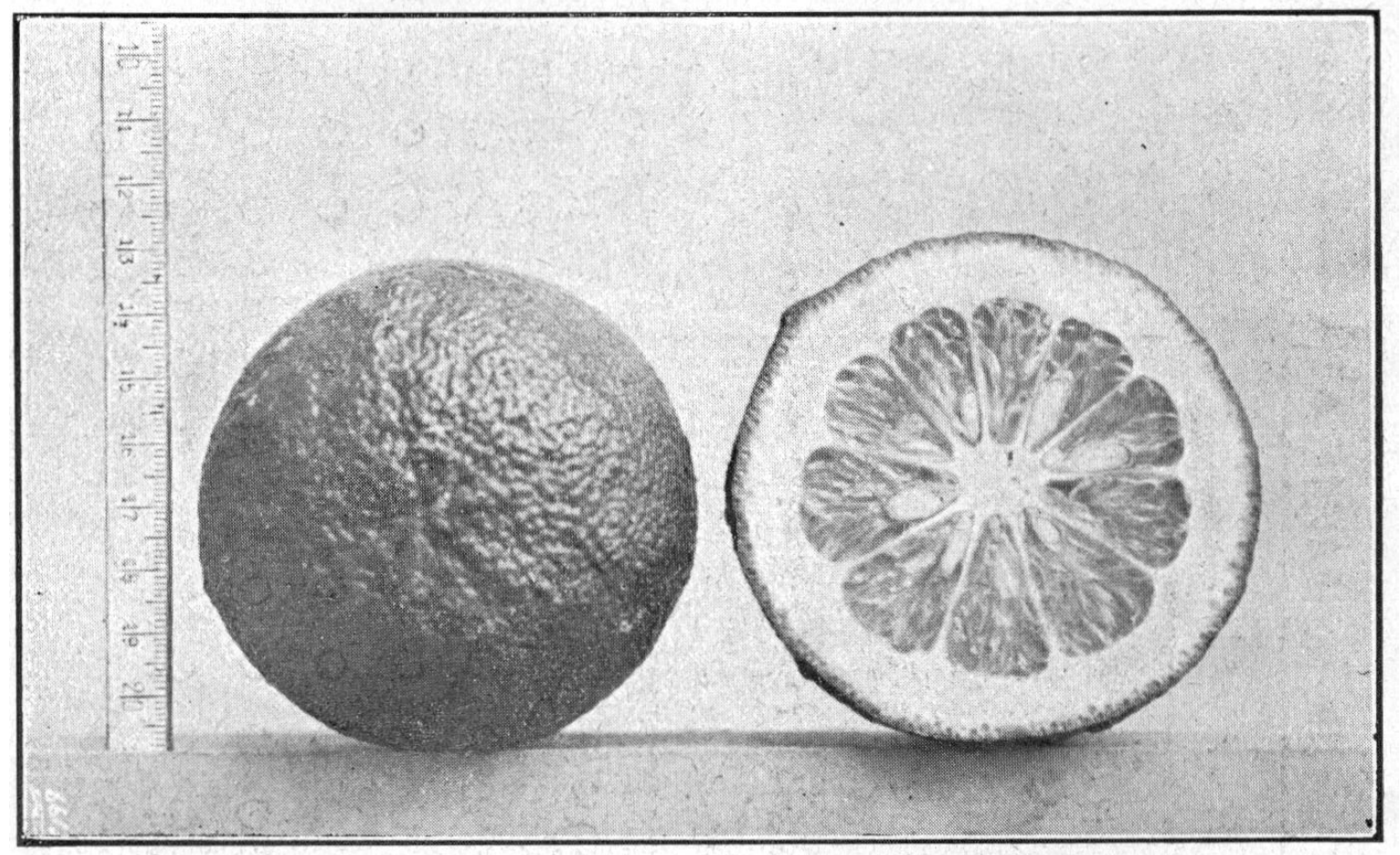

Figura 1 - Laranja azeda

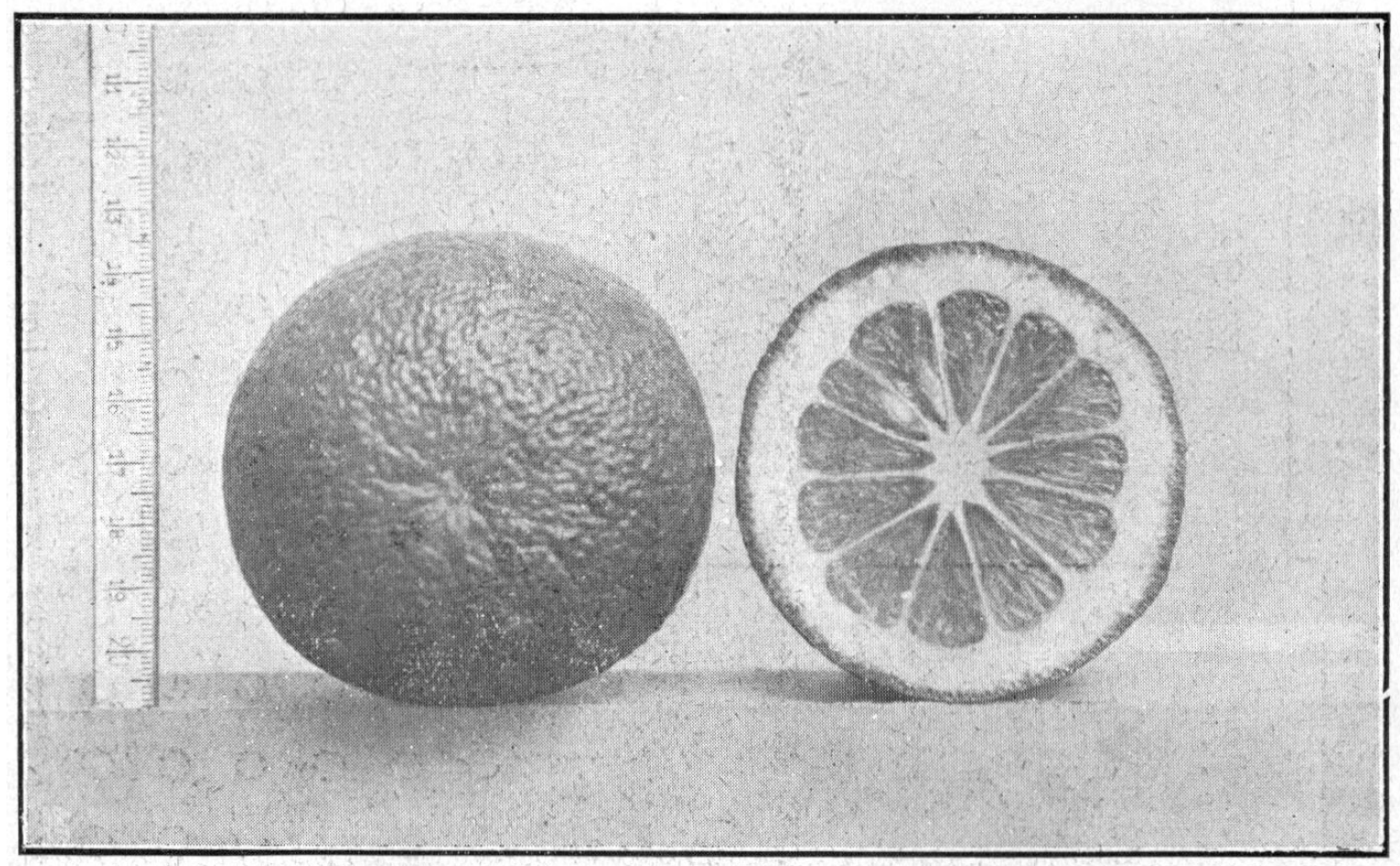

Figura 2 - Laranja agro-doce 




Figura 3 - Laranja caipira

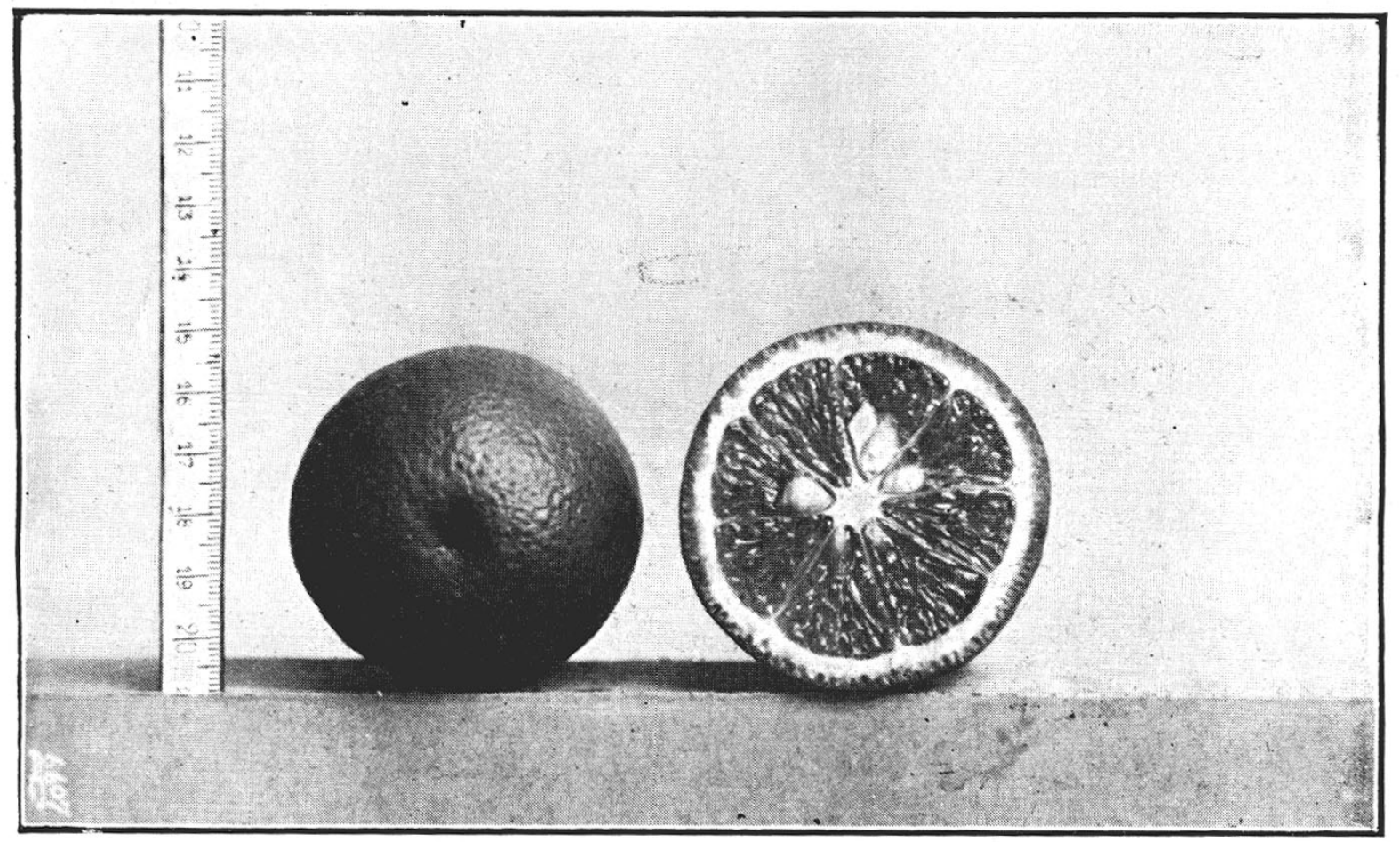

Figura 4 - Laranja lima 


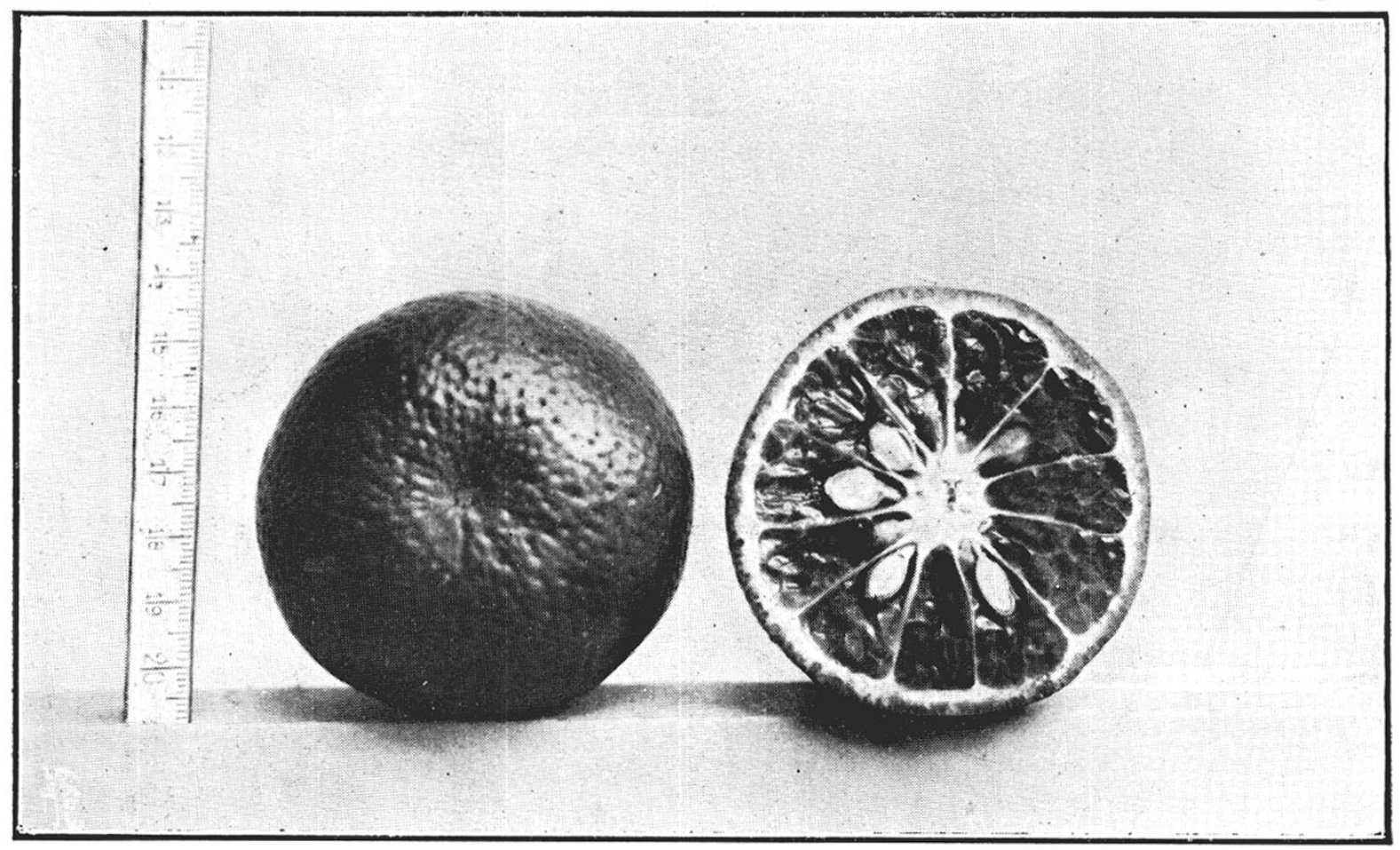

Figura 5 - Tangerira cravo

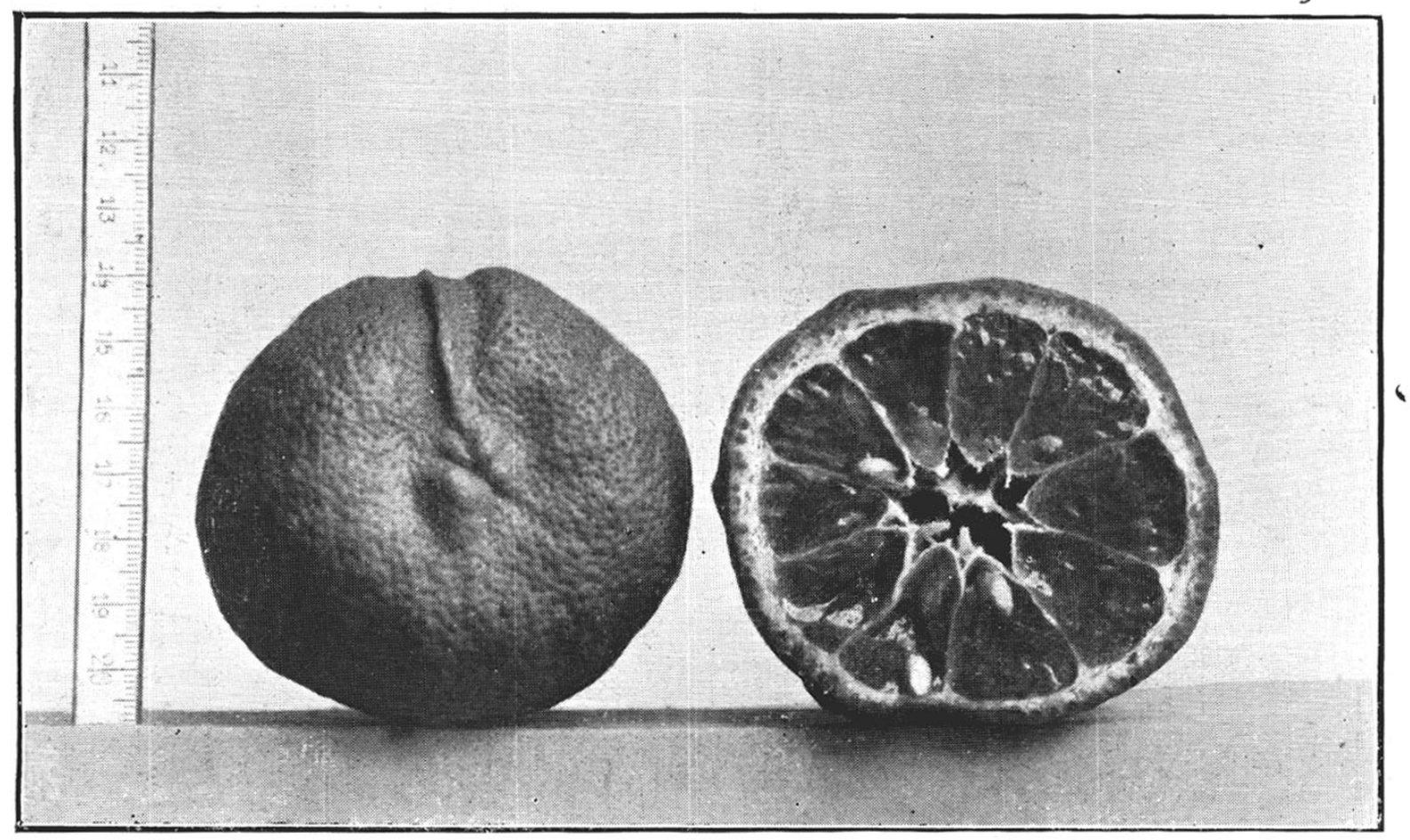

Fiqura 6 - Limão cravo 


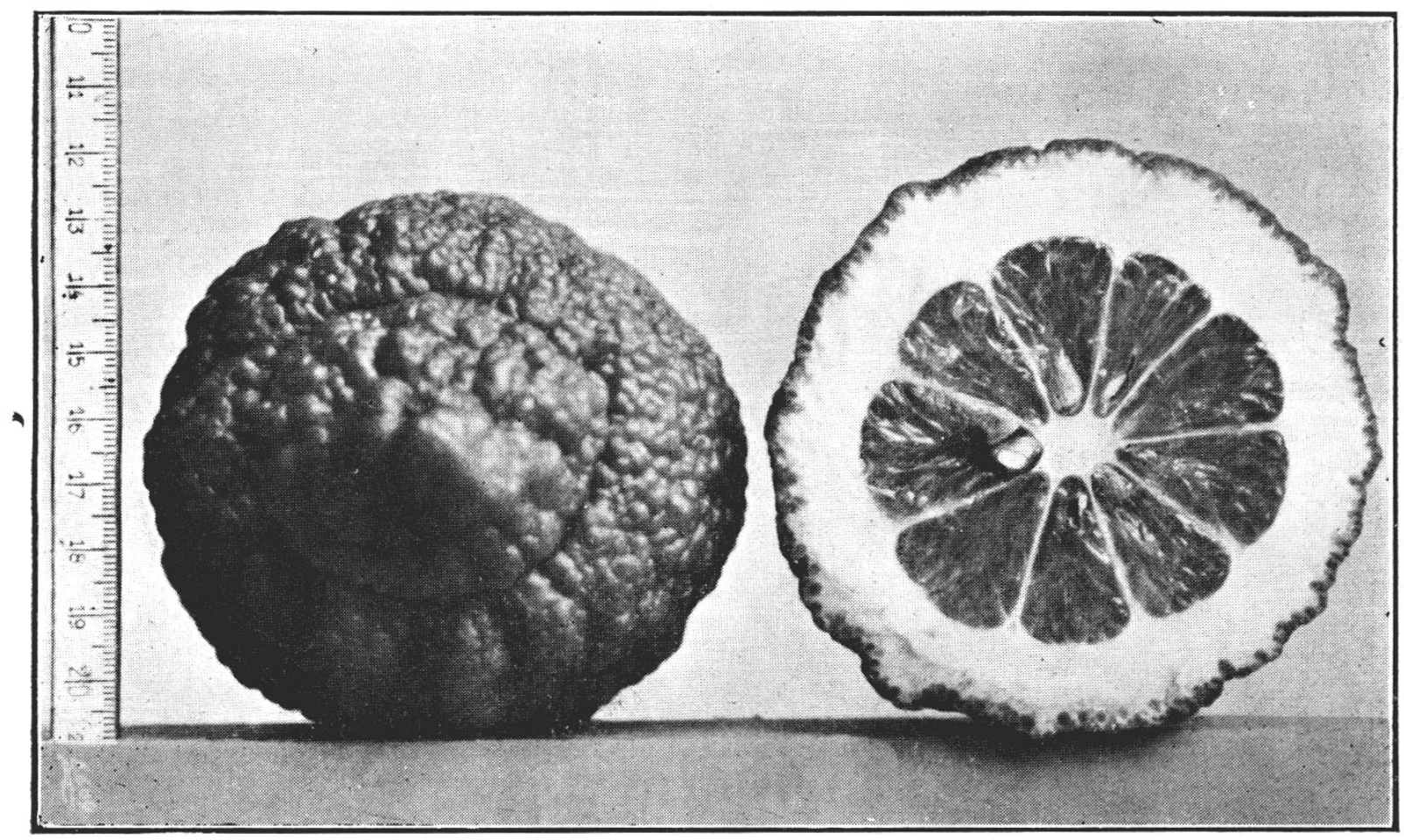

F.gura 7 - Lim气̃o rugoso

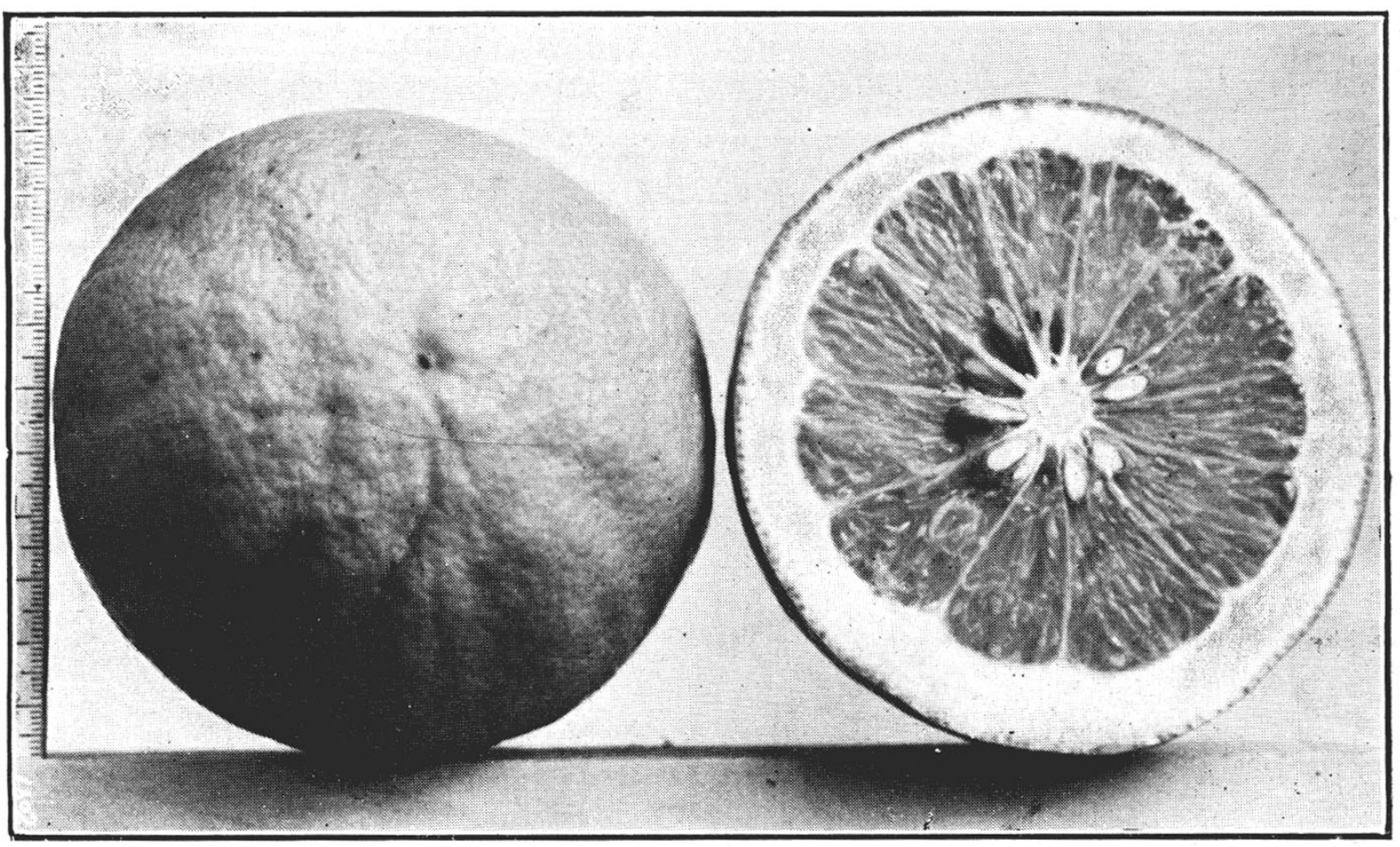

Figura 8 - Limão ponderosa 




:

Figura 9 - Lima da Pérsia

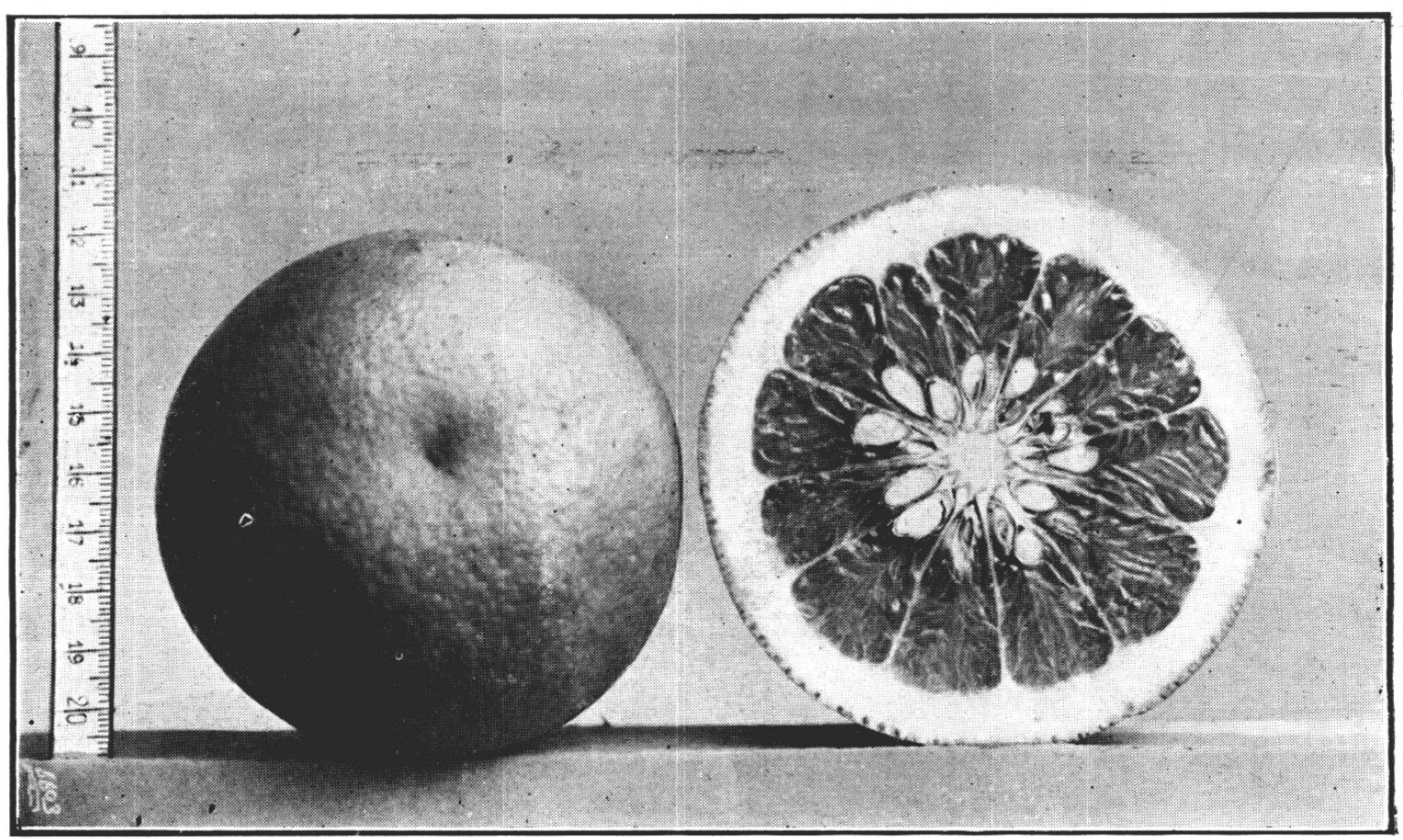

Figura 10 - Pomelo 


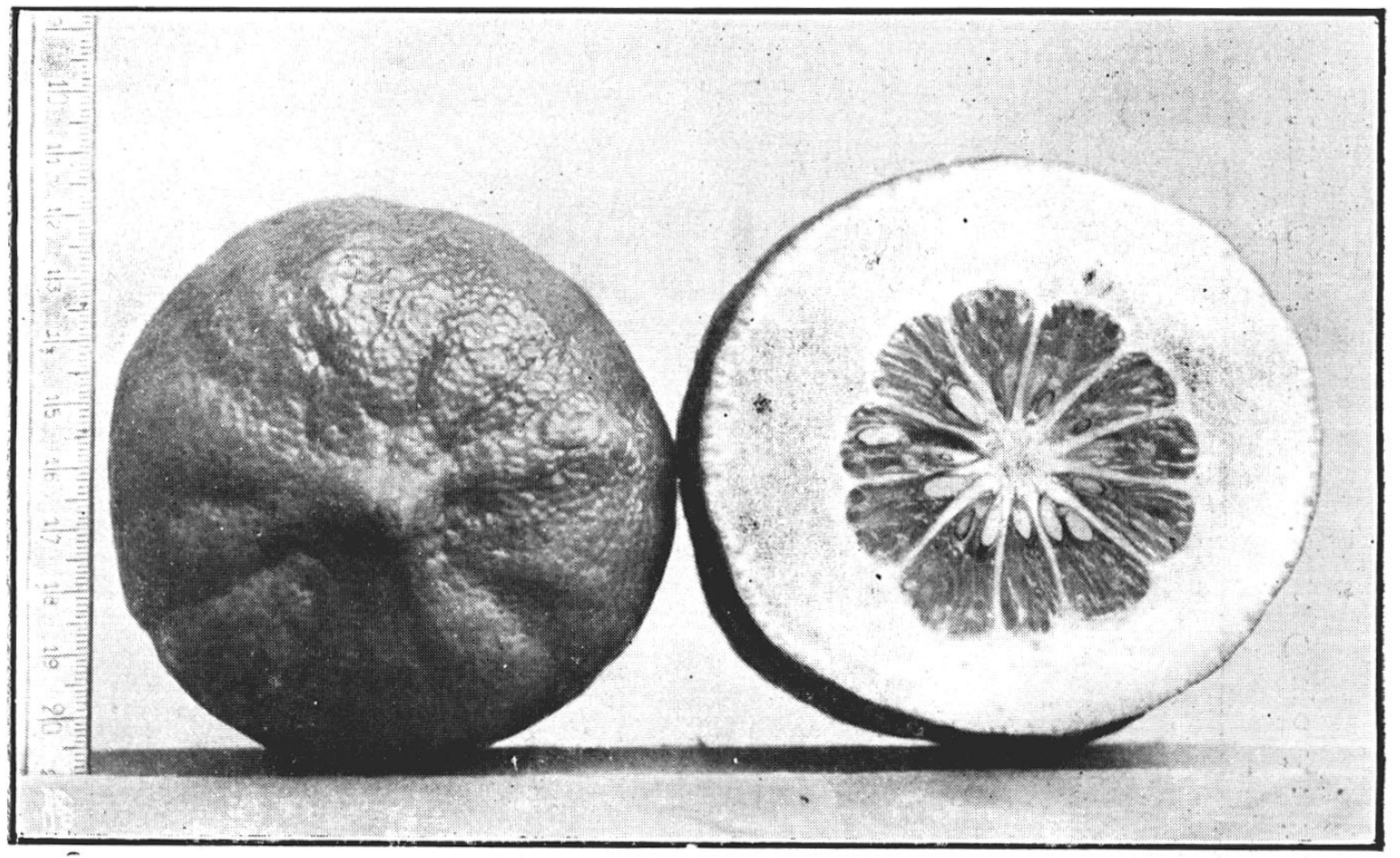

Figura 11 - Cidra

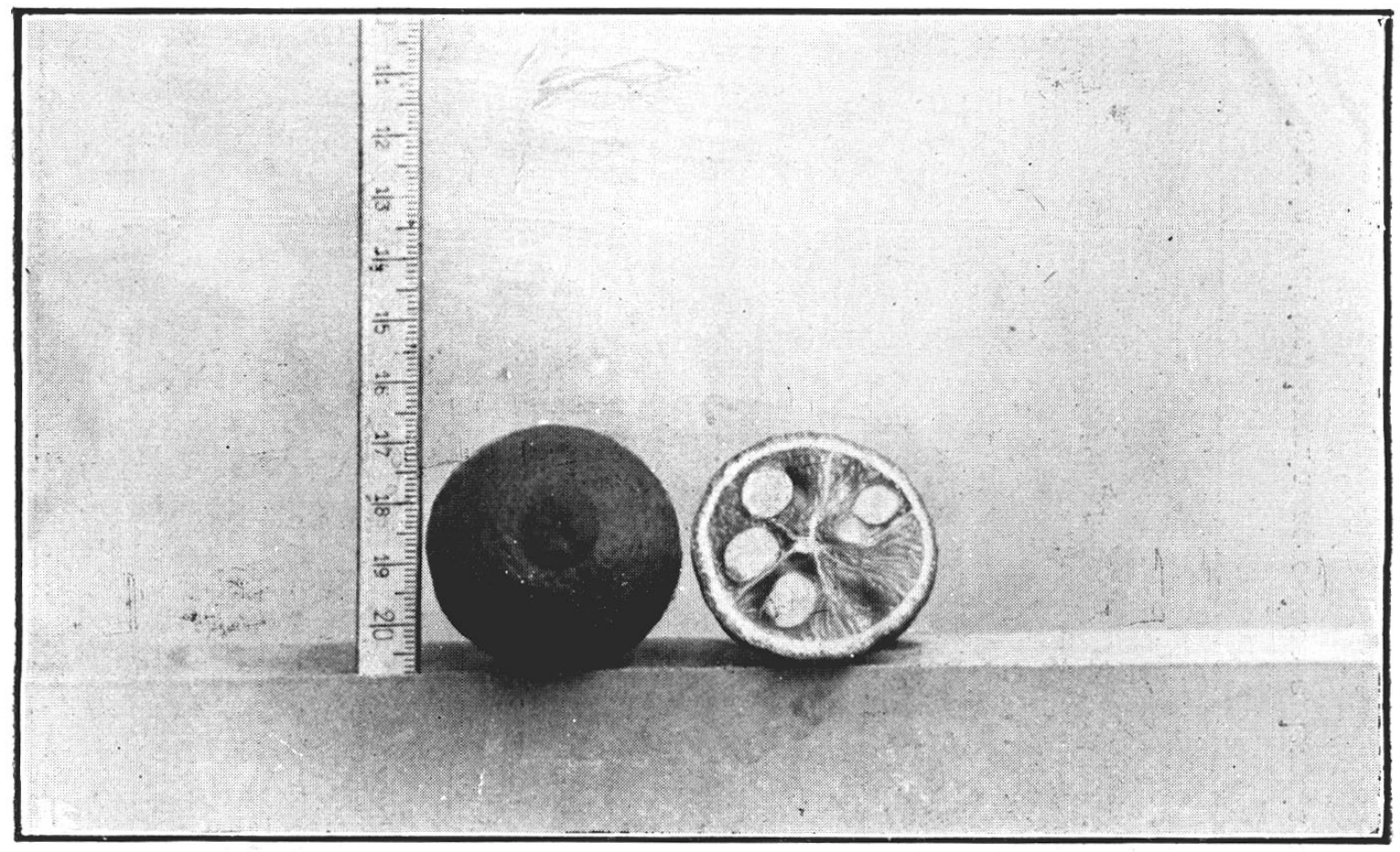

Figura 12 - Trifoliata 


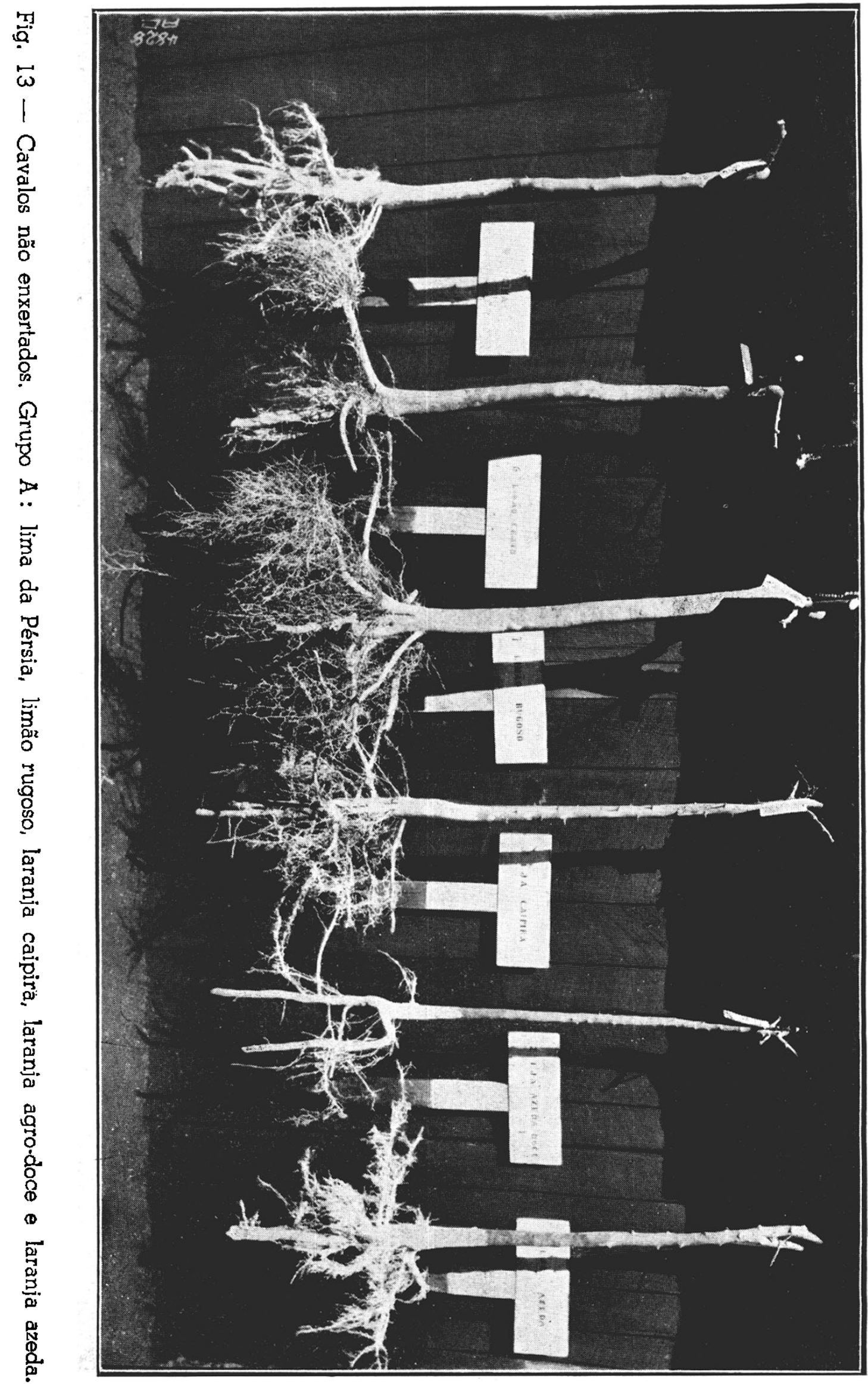




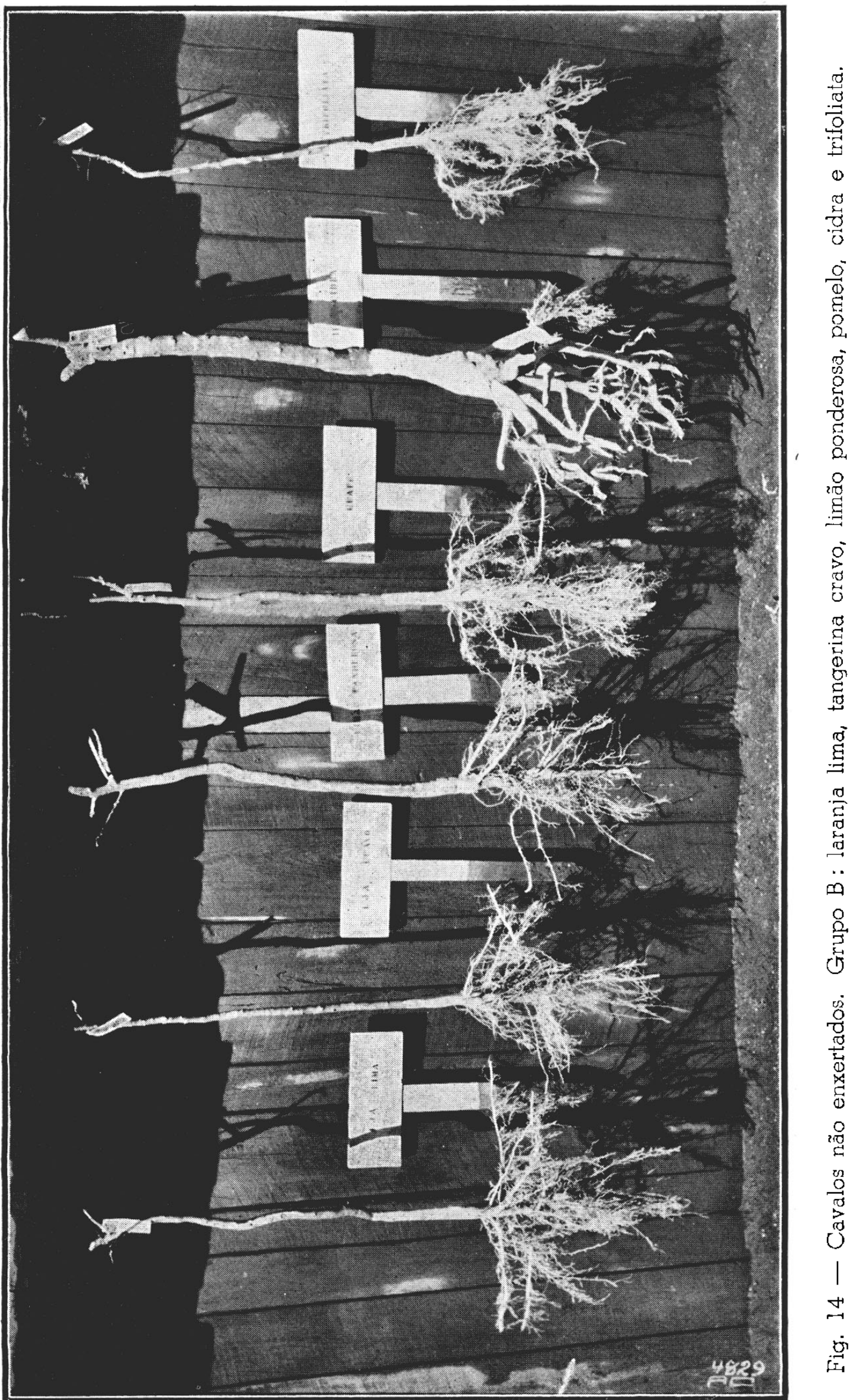




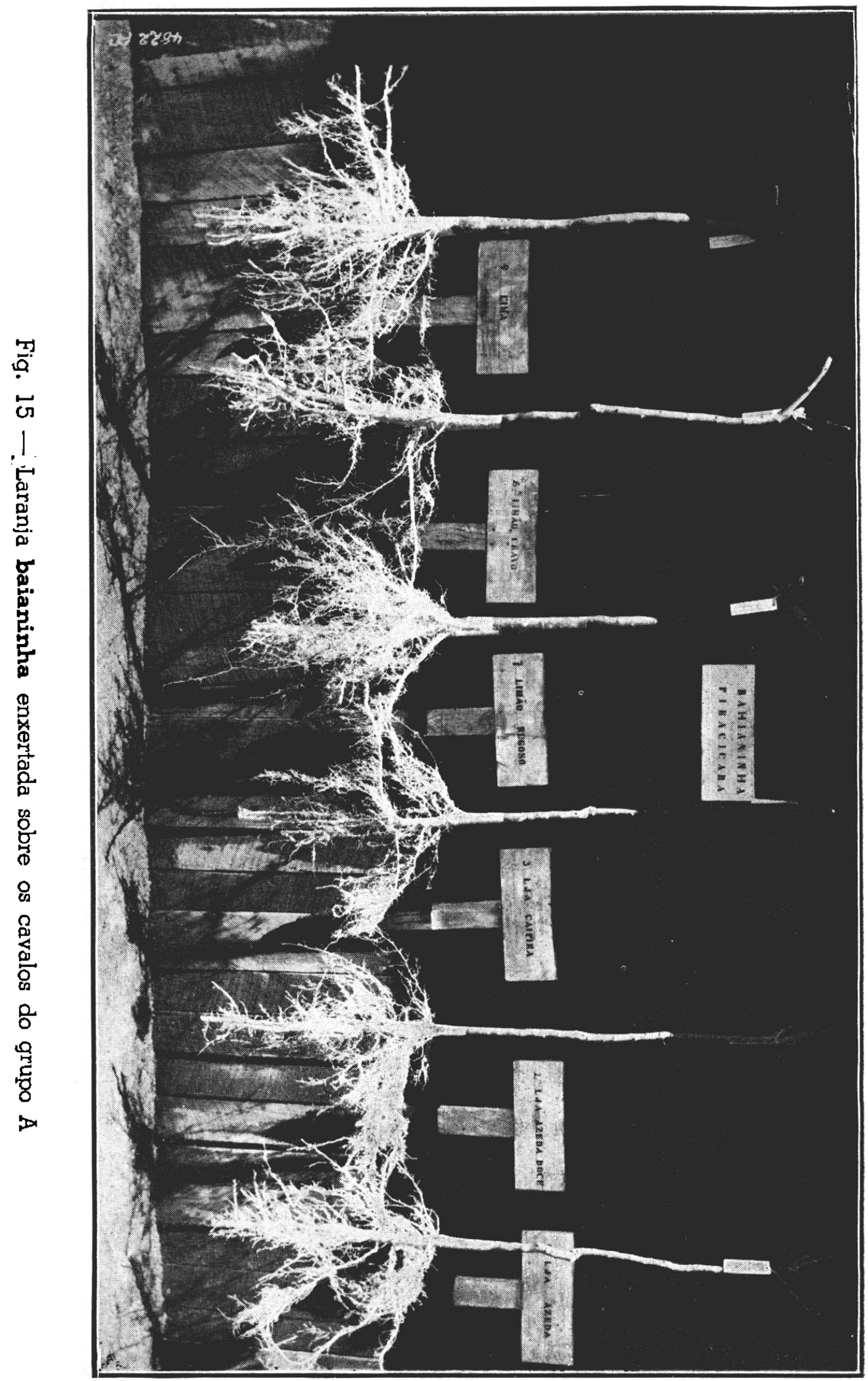




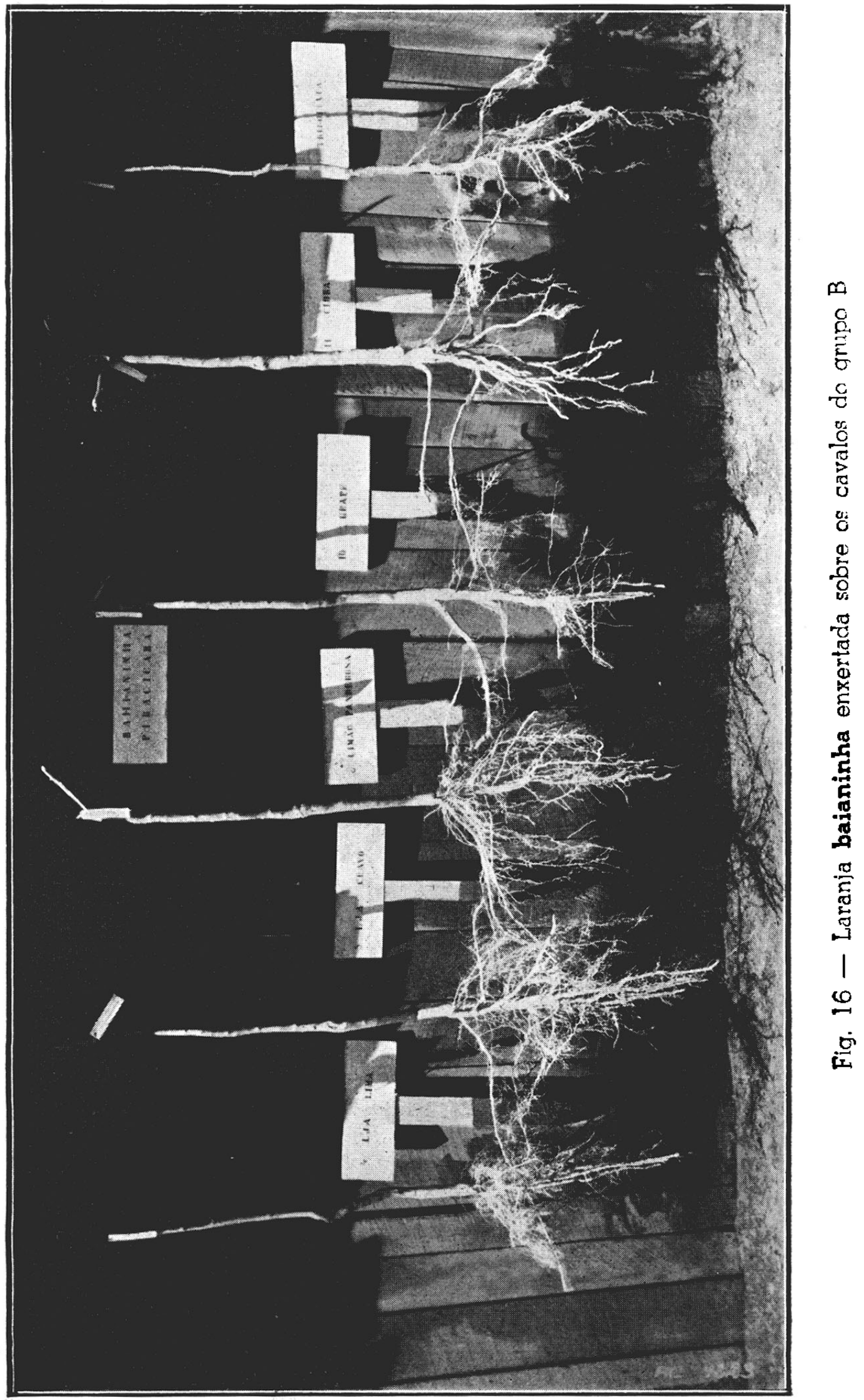




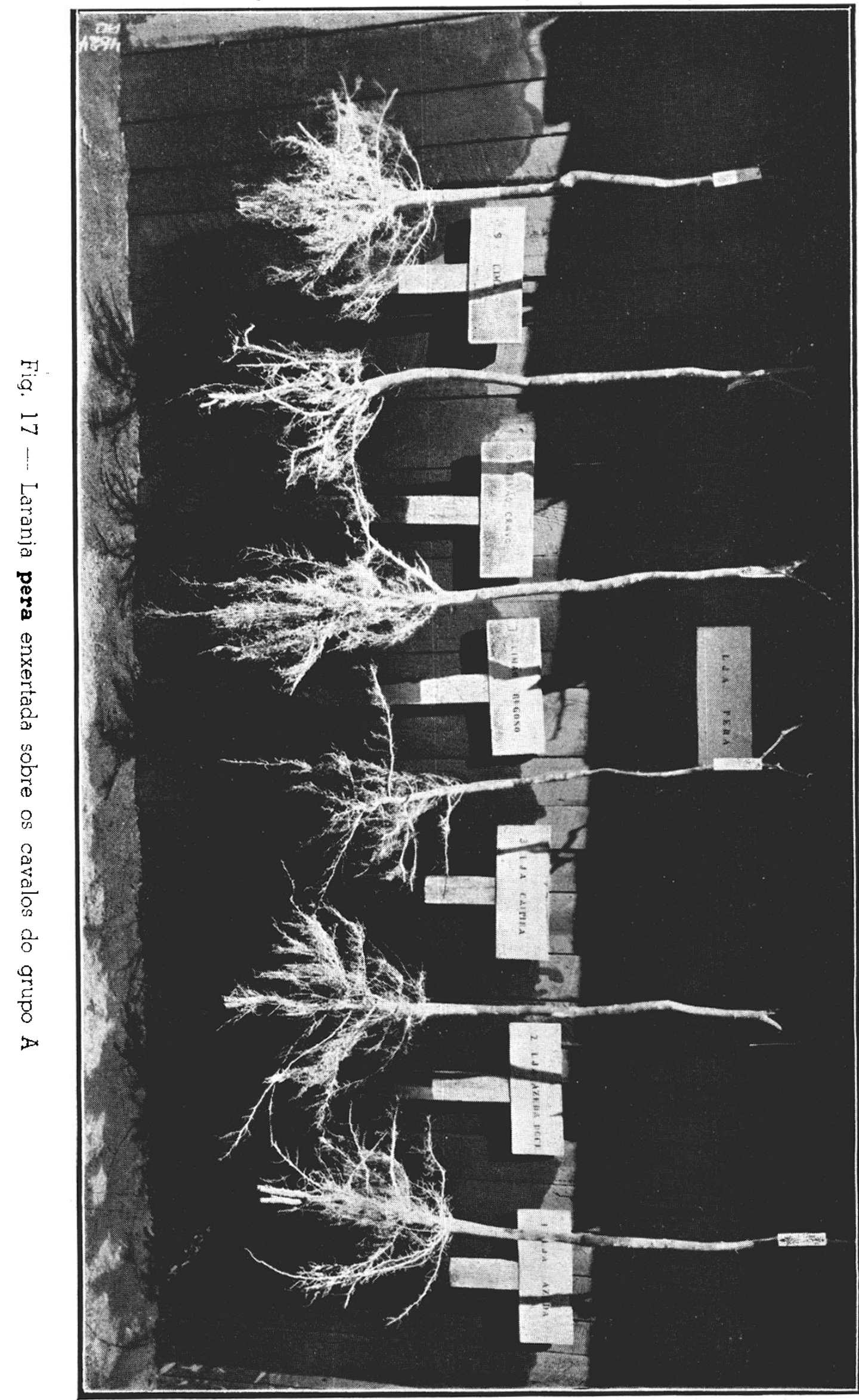




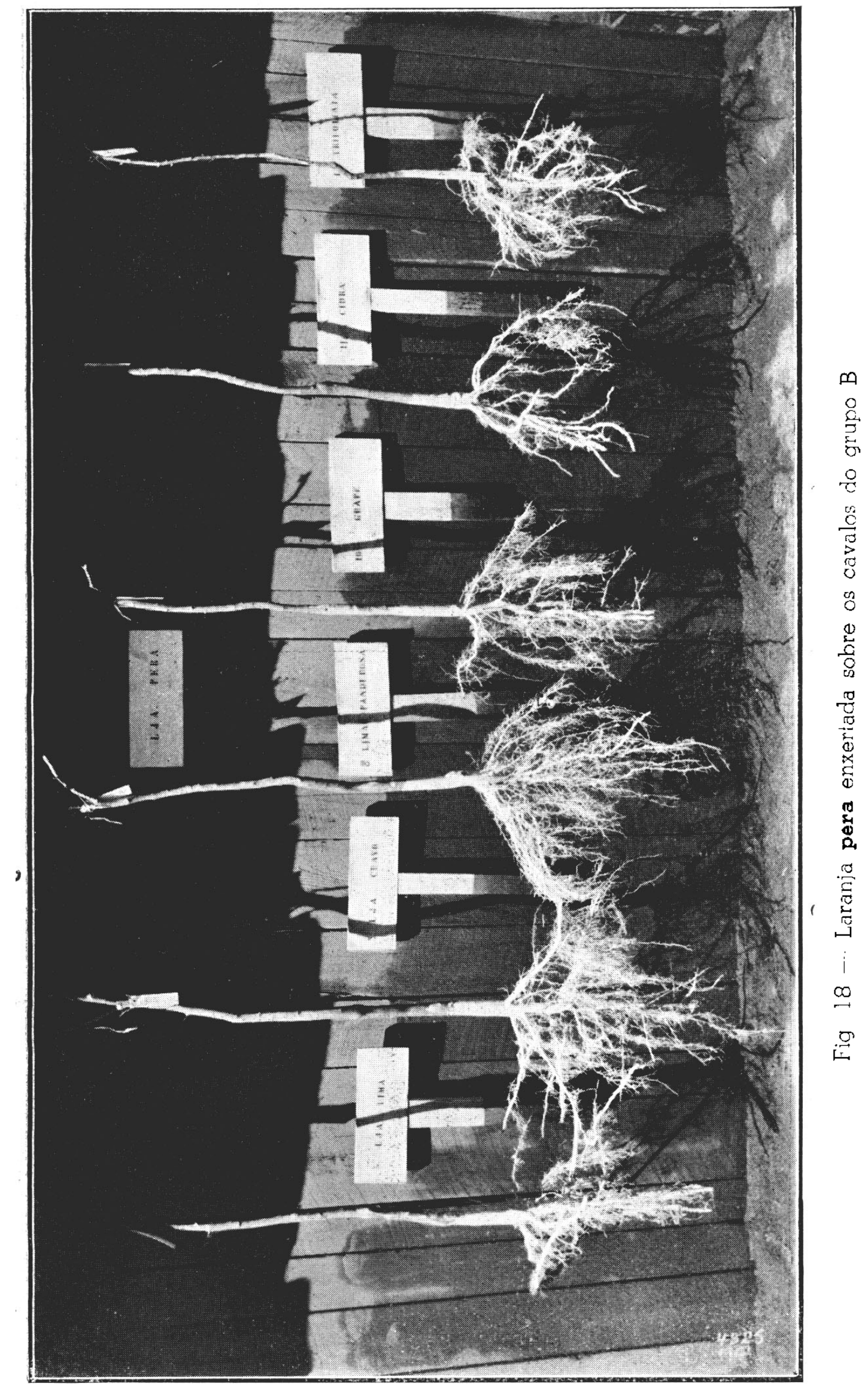




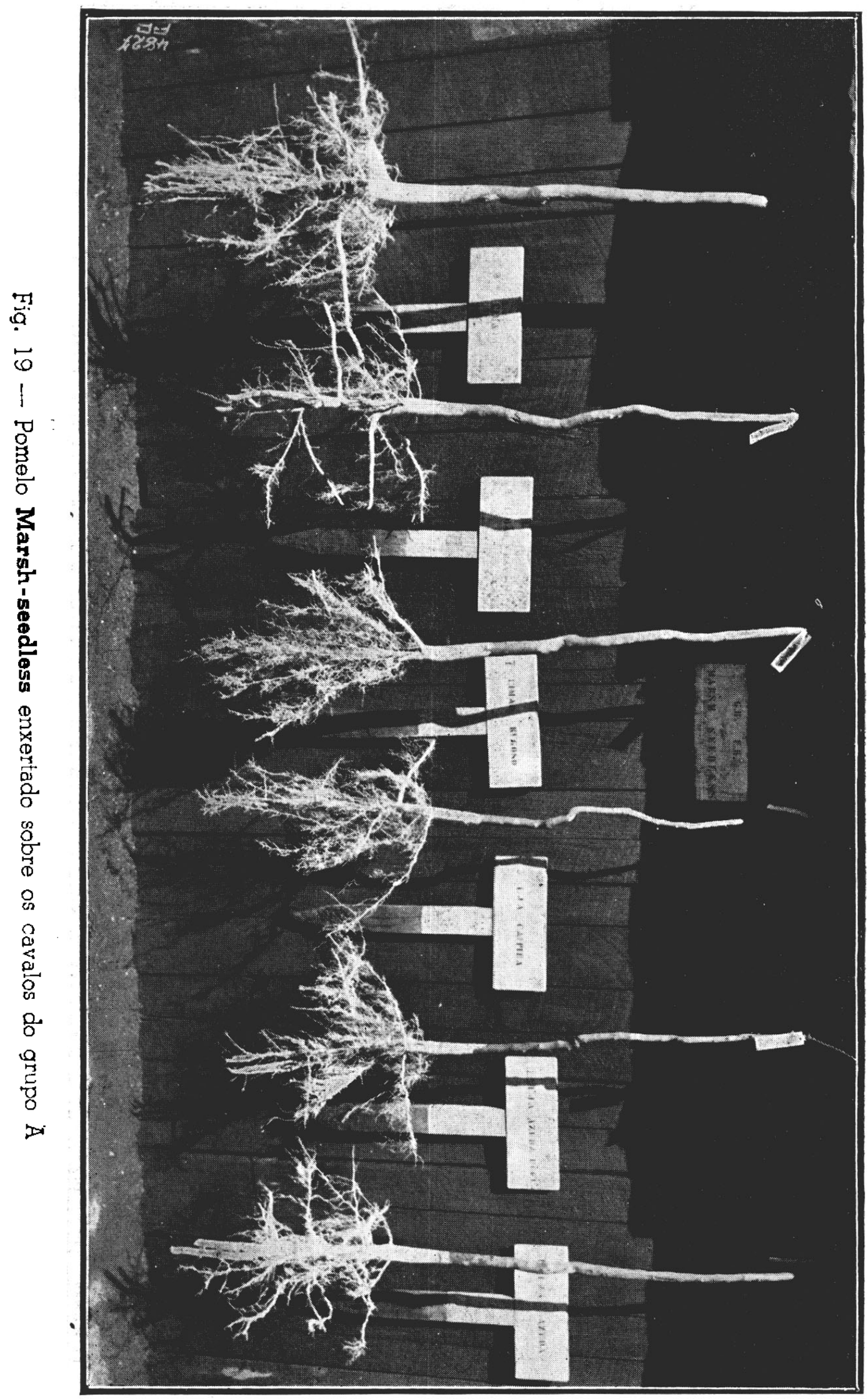




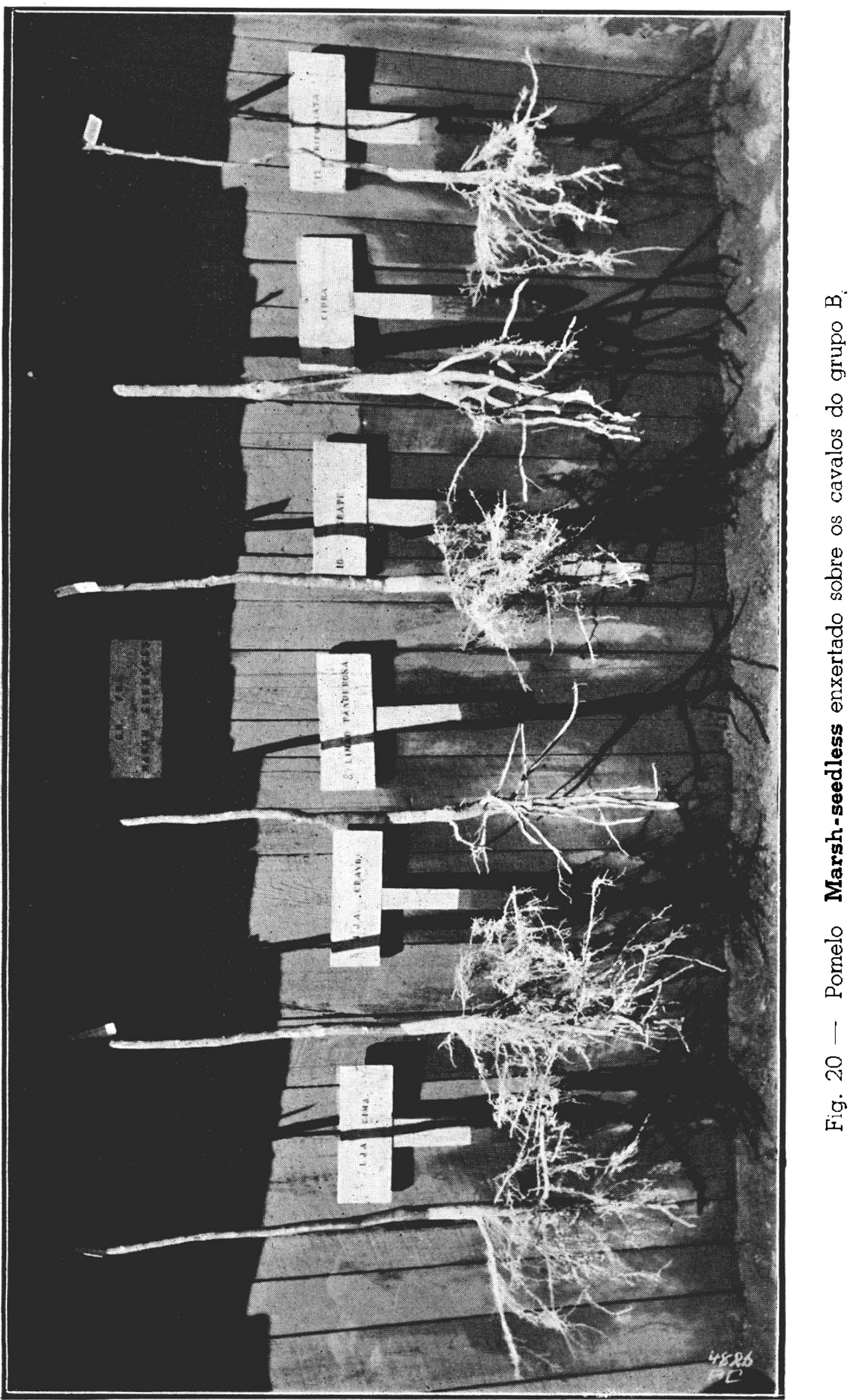

